

\title{
Intrinsic Variability of the Atlantic Meridional Overturning Circulation at Interannual-to-Multidecadal Time Scales
}

\author{
SANDY GRÉGORIO AND THIERRY PENDUFF \\ CNRS, Université Grenoble Alpes, LGGE (UMR5183), F-38041, Grenoble, France
}

GUILLAUME SÉRAZIN

CNRS, Université Grenoble Alpes, LGGE (UMR5183), F-38041, Grenoble, and Sciences de l'Univers au CERFACS, CERFACS/CNRS, URA1857, Université Paul Sabatier, Toulouse, France

JEAN-MARC MOLINES AND BERNARD BARNIER

CNRS, Université Grenoble Alpes, LGGE (UMR5183), F-38041, Grenoble, France

JOËL HIRSCHI

National Oceanography Centre, Southampton, United Kingdom

(Manuscript received 2 August 2014, in final form 14 May 2015)

\begin{abstract}
The low-frequency variability of the Atlantic meridional overturning circulation (AMOC) is investigated from $2,1 / 4^{\circ}$, and $1 / 12^{\circ}$ global ocean-sea ice simulations, with a specific focus on its internally generated (i.e., "intrinsic") component. A $327-y r$ climatological $1 / 4^{\circ}$ simulation, driven by a repeated seasonal cycle (i.e., a forcing devoid of interannual time scales), is shown to spontaneously generate a significant fraction $R$ of the interannual-to-decadal AMOC variance obtained in a 50-yr "fully forced" hindcast (with reanalyzed atmospheric forcing including interannual time scales). This intrinsic variance fraction $R$ slightly depends on whether AMOCs are computed in geopotential or density coordinates, and on the period considered in the climatological simulation, but the following features are quite robust when mesoscale eddies are simulated (at both $1 / 4^{\circ}$ and $1 / 12^{\circ}$ resolutions); $R$ barely exceeds $5 \%-10 \%$ in the subpolar gyre but reaches $30 \%-50 \%$ at $34^{\circ} \mathrm{S}$, up to $20 \%-40 \%$ near $25^{\circ} \mathrm{N}$, and $40 \%-60 \%$ near the Gulf Stream. About $25 \%$ of the meridional heat transport interannual variability is attributed to intrinsic processes at $34^{\circ} \mathrm{S}$ and near the Gulf Stream. Fourier and wavelet spectra, built from the $327-\mathrm{yr}^{1 / 4^{\circ}}$ climatological simulation, further indicate that spectral peaks of intrinsic AMOC variability (i) are found at specific frequencies ranging from interannual to multidecadal, (ii) often extend over the whole meridional scale of gyres, (iii) stochastically change throughout these $327 \mathrm{yr}$, and (iv) sometimes match the spectral peaks found in the fully forced hindcast in the North Atlantic. Intrinsic AMOC variability is also detected at multidecadal time scales, with a marked meridional coherence between $35^{\circ} \mathrm{S}$ and $25^{\circ} \mathrm{N}$ (15-30 yr periods) and throughout the whole basin (50-90-yr periods).
\end{abstract}

\section{Introduction}

The Atlantic meridional overturning circulation (AMOC) consists of two main cells that extend across the whole latitudinal range of the basin. In the upper

Corresponding author address: Sandy Grégorio, Laboratoire de Glaciologie et Géophysique de l'Environnement, LGGE/CNRS, BP 96, F-38402 Saint-Martin d'Hères cedex, France.

E-mail: sandy.gregorio@legi.grenoble-inp.fr cell, warm surface waters are advected northward; they progressively lose their heat to the atmosphere in the northern basin and become denser and sink at middepth at high latitudes to feed the southward return flow of the North Atlantic Deep Water (NADW). In the bottom cell, Antarctic Bottom Water (AABW) enters the basin from the south along the seafloor, raises upward as it mixes with lighter water, and finally recirculates and exits the basin southward within the NADW middepth flow. The AMOC upper cell's northward limb transports 
a substantial amount of heat northward, which reaches its maximum (about $1.3 \mathrm{PW}$ ) at $24^{\circ}-26^{\circ} \mathrm{N}$; this advective heat flux accounts for about $25 \%$ of the total (atmosphere and ocean) poleward heat transport at those latitudes (Hall and Bryden 1982; Johns et al. 2011). The convergence of this heat transport strongly influences the air-sea heat fluxes in the Gulf Stream region; changes in the AMOC northward limb transport may therefore have substantial climatic impacts (Dong et al. 2007).

Observational programs, developed in the last decade, are monitoring the AMOC strength, structure, and variability: the RAPID-MOCHA program (Hirschi et al. 2003; Baehr et al. 2004; Cunningham et al. 2007; Kanzow et al. 2007; McCarthy et al. 2012) started in 2004 and continuously monitors the AMOC at the $26.5^{\circ} \mathrm{N}$ latitude; the Meridional Overturning Variability Experiment (MOVE) program (Send et al. 2002) started in 2000 and is focused on $16^{\circ} \mathrm{N}$; and the Observatoire de la Variabilité Interannuelle et Décennale en Atlantique Nord (OVIDE) program (Lherminier et al. 2007) has been monitoring a section from Greenland to Portugal every other year since 2002. The mechanisms of AMOC variability have also been studied numerically (e.g., Delworth et al. 1993; Bentsen et al. 2004) throughout the whole basin and on much longer time scales, either from ocean simulations driven by atmospheric reanalyses (in laminar or eddying regimes) or from coupled oceanatmospheric simulations (mostly in the laminar regime).

Most studies to date about the AMOC variability in the eddying regime have been concerned with the response of the AMOC to a prescribed atmospheric variability. Using ocean general circulation models (OGCMs), Biastoch et al. (2008) and Hirschi et al. (2013) have documented another aspect of the interannual-to-decadal variability of the AMOC computed along geopotential levels. Both studies revealed that when mesoscale eddies are (even partially) resolved, nonlinearities become significant and the phase of the AMOC time series is no longer locked to the phase of the atmospheric forcing: it becomes partly chaotic, up to decadal time scales. Using a laminar global OGCM with an increase in resolution in the Agulhas region driven by an atmospheric reanalysis, Biastoch et al. (2008) showed that resolving mesoscale eddies locally strongly modifies the phase of the decadal variability of the AMOC northward limb transport (approximated by the AMOC time series at $1000 \mathrm{~m}$ ); this phase perturbation was maximum in the Agulhas region but did propagate as far as the Northern Hemisphere subtropics within a few months. Hirschi et al. (2013) then compared the AMOC northward limb transport time series obtained from two eddy-permitting $\left(1 / 4^{\circ}\right)$ global OGCM hindcasts with different initial conditions but identical surface forcing. The chaotic interannual-to-decadal AMOC variability component, revealed by substantial differences between individual time series, was shown to account for a significant proportion of the total AMOC interannual variance found in individual hindcasts: around $15 \%-35 \%$ throughout the South Atlantic, $10 \%$ between the equator and $25^{\circ} \mathrm{N}$, $15 \%-20 \%$ between $25^{\circ}$ and $47^{\circ} \mathrm{N}$, and about $5 \%$ farther north. ${ }^{1}$ Both Biastoch et al. (2008) and Hirschi et al. (2013) thus identified substantial chaotic AMOC variability, some of which may be generated in the South Atlantic and propagate to the north.

The present study uses a different strategy to further investigate how the low-frequency (LF; i.e., at time scales longer than $1 \mathrm{yr}$ ) variability of the AMOC uppercell northward limb transport is impacted by intrinsic oceanic processes. As done in Penduff et al. (2011), we mainly compare two global $1 / 4^{\circ}$ OGCM simulations: one 50 -yr hindcast forced by the full range of observed atmospheric time scales and one 327-yr run forced each year by the same climatological atmospheric annual cycle. The "fully forced" run is comparable to Hirschi et al.'s (2013) hindcasts and yields the so-called total AMOC variability over the last decades. The seasonally forced run isolates the AMOC LF variability that is intrinsic, that is, generated by the ocean without any forcing at these time scales. Using this or similar approaches, Penduff et al. (2011) and Thomas and Zhai (2013) showed the substantial imprint of interannual-todecadal intrinsic variability on sea surface height and AMOC, respectively. Penduff et al. (2011) also demonstrated that switching to the laminar regime $\left(2^{\circ}\right)$ almost suppresses sea level intrinsic variability.

The simulation strategies mentioned above yield complementary views on the LF variability that spontaneously emerges in the eddying ocean. Both Biastoch et al. (2008) and Hirschi et al. (2013) used a pair of fully forced hindcasts, one of which was perturbed (through a local increase of resolution and through perturbed initial conditions, respectively). Differences between both hindcasts were used by these authors to estimate the imprint of intrinsic variability under full forcing but with two limitations: time scales of interest could not extend beyond one decade or so since atmospheric reanalyses have limited duration and since the estimate of intrinsic variability intensity (derived from two-member ensemble dispersions) probably has a sizeable inaccuracy. Unlike these authors, Thomas and Zhai (2013) used atmospheric forcing fields devoid of any low frequency,

\footnotetext{
${ }^{1}$ Hirschi et al.'s (2013) Fig. 14c presents this proportion in terms of AMOC standard deviations at low frequencies.
} 
hence isolating in the North Atlantic the purely intrinsic (i.e., disentangled from its atmospherically forced counterpart) LF ocean variability over still relatively short 15-yr simulations. Note that Penduff et al. (2011) also used short 12-yr datasets to study the sea level intrinsic variability. In the present study, we follow Penduff et al.'s (2011) and Thomas and Zhai's (2013) climatological forcing strategy to study the purely intrinsic LF variability, but over a much longer, 327-yr global integration; interannual-to-decadal intrinsic variability is first estimated from statistics based on nine successive 32-yr periods; its multidecadal and intermittent behavior is then analyzed from 309-yr time series.

Our first objective here is to quantify from the $327-\mathrm{yr}$ seasonally forced simulation the intensity of the intrinsic interannual-to-decadal AMOC variability, its stability over successive 32-yr periods, and its relative contribution to the total AMOC variance simulated with full forcing. Our second objective is to discuss from these results the potential contribution of intrinsic variability on existing and future AMOC monitoring data [i.e., RAPID and OVIDE and Overturning in the Subpolar North Atlantic Program (OSNAP) and South Atlantic Meridional Overturning Circulation Initiative (SAMOC), respectively; see Schiermeier 2013] and on the meridional heat transport (MHT) at these key latitudes. Our third objective is to examine the sensitivity of these results to model resolution, ranging from $2^{\circ}$ (laminar regime) through $1 / 4^{\circ}$ (eddy permitting) up to $1 / 12^{\circ}$ (eddy resolving). We will finally describe the temporal behavior of the intrinsic AMOC LF variability throughout the whole seasonally forced run, including time scales longer than one decade.

Our numerical simulations and postprocessing techniques are presented in section 2. The intensity of intrinsic and total AMOC variabilities will be compared over $\sim 1-10$-yr time scales throughout the basin (section 3 ), first at $14^{\circ}$ resolution, then focusing on resolution impacts. The longer-term behavior of the intrinsic variability, its dominant time scales, and meridional coherence of its multidecadal time scales will then be studied from the long $327-y r$ seasonally forced $1 / 4^{\circ}$ simulation (section 4). Conclusions are given in section 5.

\section{Model simulations and processing}

\section{a. Model simulations}

Each pair of simulations used in this study includes a fully forced " $F$ " run and a seasonally forced " $S$ " run that differ only in their forcing. F simulations are intended to mimic the evolution of the observed ocean, and S simulations isolate the intrinsic part of the low-frequency variability. Each pair corresponds to a specific horizontal resolution $\left(2^{\circ}, 1 / 4^{\circ}\right.$, and $\left.1 / 12^{\circ}\right)$ and associated subgridscale parameterizations.

These six simulations were performed in the framework of the DRAKKAR project using the Nucleus for European Modeling of the Ocean (NEMO; Madec et al. 2012) ocean-sea ice numerical model with the same 46level vertical discretization. The six simulations share a partial cell representation of topography and a momentum advection scheme that conserves energy and enstrophy (Barnier et al. 2006; Penduff et al. 2007; Le Sommer et al. 2009); a total variance diminishing (TVD) tracer advection scheme; an isopycnal Laplacian tracer diffusion operator; a vertical mixing scheme based on the TKE turbulent closure model (Blanke and Delecluse 1993); and a convective adjustment scheme based on enhanced vertical mixing in case of static instability.

Table 1 summarizes the main differences between these simulations. Note that the $2^{\circ}$ and $1 / 4^{\circ}$ configurations and simulations used here are described in detail in Penduff et al. (2010, 2011). The $1 / 12^{\circ}$ model configurations are described in detail in Molines et al. (2014); the seasonally forced $1 / 12^{\circ}$ simulation has been analyzed in Treguier et al. (2014) and Deshayes et al. (2013). More information about model configurations and solutions may be found in the aforementioned papers as well as in Sérazin et al. (2015).

Each pair of simulations composes a 50-yr fully forced F run driven by the full range of atmospheric time scales available in original datasets (6-hourly forcing from 1958 to 2007) and a seasonally forced S run driven by its corresponding climatological annual cycle; the forcing of both simulations within a pair is based on the same original forcing dataset (see Table 1); the method we used to generate the climatological annual cycle from the full forcing is described in Penduff et al. (2011). The original forcing dataset used for the $2^{\circ}$ and $1 / 4^{\circ}$ pairs is referred to as DFS4. The original forcing dataset DFS4.4 used for our $1 / 12^{\circ}$ pair is described in detail in Dussin and Barnier (2013) and differs from DFS4 only after 31 December $2001 .^{2}$

\section{b. AMOC computation}

The first $18 \mathrm{yr}$ are discarded from all simulations; this removes from AMOC time series the imprint of initial

\footnotetext{
${ }^{2}$ Use of ERA-Interim instead of ERA-40 for all forcing variables: wind vector, air temperature and humidity, downward shortwave and longwave radiation, total precipitation, and snowfall. Corrections described in Brodeau et al. (2010) ensure a smooth transition in 2001/02. ERA-Interim variables, whose native resolution is $0.7^{\circ}$ and $3 \mathrm{~h}$, were projected at ERA-40 resolution $\left(1.125^{\circ}\right.$ and $6 \mathrm{~h})$.
} 
TABLE 1. Model setups and simulations.

\begin{tabular}{|c|c|c|c|}
\hline Horizontal resolution $^{\mathrm{a}}$ & $2^{\circ}$ & $1 / 4^{\circ}$ & $1 / 12^{\circ}$ \\
\hline Meridional grid refinement & $1 / 3^{\circ}$ (equator) & \multicolumn{2}{|c|}{ None } \\
\hline NEMO version & & 2.3 & 3.4 \\
\hline Horizontal viscosity operator & Laplacian & \multicolumn{2}{|c|}{ Biharmonic } \\
\hline Horizontal viscosity (equator) ${ }^{\mathrm{b}}$ & Specific ${ }^{c}$ & $1.5 \times 10^{11} \mathrm{~m}^{4} \mathrm{~s}^{-1}$ & $1.25 \times 10^{10} \mathrm{~m}^{4} \mathrm{~s}^{-1}$ \\
\hline Isopycnal diffusion (equator) ${ }^{\mathrm{d}}$ & Specific ${ }^{\mathrm{e}}$ & $300 \mathrm{~mm} \mathrm{~s}^{-1}$ & $100 \mathrm{~mm} \mathrm{~s}^{-1}$ \\
\hline Lateral boundary conditions & No slip & \multicolumn{2}{|c|}{ Free slip } \\
\hline Original forcing dataset & \multicolumn{2}{|r|}{ DFS4 $4^{\mathrm{f}}$} & DFS4.4 \\
\hline Sea surface salinity $(\mathrm{SSS})$ restoring time scale [days $(10 \mathrm{~m})^{-1}$ ] & \multicolumn{2}{|r|}{60} & $60^{\mathrm{g}}$ \\
\hline AABW restoring & \multicolumn{2}{|r|}{ None } & 2-yr time scale ${ }^{\mathrm{h}}$ \\
\hline F runs: simulation name & ORCA246-G83b & ORCA025-B83 & ORCA12-MJM88 \\
\hline F runs: integration period & \multicolumn{3}{|c|}{1 Jan 1958-31 Dec 2007 (50 yr) } \\
\hline$S$ runs: simulation name & ORCA246-MJM01 & 1 ORCA025-MJM01 & ORCA12-GJM02 \\
\hline$S$ runs: integration length & $327 \mathrm{yr}$ & $327 \mathrm{yr}$ & $85 \mathrm{yr}$ \\
\hline
\end{tabular}

${ }^{\text {a }}$ At the equator.

${ }^{\mathrm{b}}$ Scales as the square of grid step.

${ }^{c}$ Cravatte et al. (2007)

${ }^{\mathrm{d}}$ Laplacian; scales as the grid step.

${ }^{\text {e }}$ Cravatte et al. (2007)

${ }^{\mathrm{f}}$ Brodeau et al. (2010)

${ }^{\mathrm{g}}$ Model SSS is smoothed prior to subtraction from Levitus SSS; restoring tends to zero toward continents over a 150-km typical scale; corrective freshwater flux limited to $4 \mathrm{~mm} \mathrm{day}^{-1}$.

${ }^{\mathrm{h}}$ Within the AABW density range, below $1000 \mathrm{~m}$ and south of $30^{\circ} \mathrm{S}$. See Dufour et al.'s (2012) appendix.

dynamical adjustments and ensures that their long-term adjustment trends are well captured (and removed) by the Loess high-pass filtering process. Total (fully forced) AMOC LF statistics are thus computed from $F$ runs over the 32-yr 1976-2007 period. Intrinsic (seasonally forced) AMOC LF statistics are computed from various segments of the $\mathrm{S}$ run time series, depending on the questions addressed and available data, either from the whole S run (i.e., years $19-327$ at $1 / 4^{\circ}$ ) or from successive 32-yr segments: two segments (years 19-50 and 51-82) at $1 / 12^{\circ}$ and nine segments $(19-50,51-82, \ldots, 275-306)$ at $1 / 4^{\circ}$ and $2^{\circ}$ that will be combined into a pseudoensemble for some statistics.

AMOCs are computed in both geopotential and potential density referenced to $2000-\mathrm{m} \sigma_{2}$ coordinates from monthly model outputs. These monthly values are then averaged over 12 months to yield yearly $\mathrm{AMOC}_{z}$ and $\mathrm{AMOC}_{\sigma_{2}}$ estimates (also see section 2e). The impact of the model resolution will only be estimated in terms of $\mathrm{AMOC}_{z}$ since the absence of monthly temperature and salinity (hence density) files prevented us from computing $\mathrm{AMOC}_{\sigma_{2}}$ in certain simulations. All other analyses, however, will take advantage of $\mathrm{AMOC}_{\sigma_{2}}$ estimates. In accordance with Zhang (2010), our $14^{\circ}$ $\mathrm{AMOC}_{\sigma_{2}}$ captures the diapycnal water mass transformation (DWT). At high latitudes in particular (i.e., a region where steep isopycnals are common) there therefore can be substantial differences between $\mathrm{AMOC}_{\sigma_{2}}$ and $\mathrm{AMOC}_{z}$ as the latter represents sinking and not DWT. Similar values are typically found for both $\mathrm{AMOC}_{\sigma_{2}}$ and $\mathrm{AMOC}_{z}$ in low to midlatitudes where isopycnals are flatter. We shall follow Zhang (2010) on a second point: the transports of the AMOC upper-cell northward limb are estimated every year at each latitude as the maximum of AMOC streamfunctions in depth and density (for $\mathrm{AMOC}_{z}$ and $\mathrm{AMOC}_{\sigma_{2}}$, respectively).

\section{c. Comparison of mean $A M O C_{\sigma_{2}}$ in $1 / 4^{\circ}$ runs}

Figures $1 \mathrm{a}$ and $1 \mathrm{~b}$ show that our $\mathrm{F}$ and $\mathrm{S} 1 / 4^{\circ}$ simulations yield very similar time-averaged $\mathrm{AMOC}_{\sigma_{2}}$ streamfunctions, in particular in the $36-37 \mathrm{~kg} \mathrm{~m}^{-3}$ density range. In this range, the magnitude $[\sim 20.5$ Sverdrups $\left.\left(\mathrm{Sv} ; 1 \mathrm{~Sv} \equiv 10^{6} \mathrm{~m}^{3} \mathrm{~s}^{-1}\right)\right]$ and location $\left(55^{\circ} \mathrm{N}, 36.7 \mathrm{~kg} \mathrm{~m}^{-3}\right)$ of both overturning maxima are almost indistinguishable. The meridional distributions of upper-cell timemean intensities (Fig. 1c) differ by less than $2 \%$ throughout the whole basin, except between $66^{\circ}$ and $70^{\circ} \mathrm{N}$, where this difference reaches $10 \%$. In other words, the differences in atmospheric forcings barely affect the time-mean $\mathrm{AMOC}_{\sigma_{2}}$ structure and intensity over $50 \mathrm{yr}$, hence ensuring that differences in variabilities obtained in $\mathrm{F}$ and $\mathrm{S}$ runs are not due to different mean states.

\section{d. Nonlinear detrending}

Any OGCM progressively adjusts toward its own "climate," hence explaining nonlinear trends in certain time series. The blue line in Fig. 2 shows that this adjustment yields an $8 \%$ decrease in $\mathrm{AMOC}_{\sigma_{2}}$ at $26.5^{\circ} \mathrm{N}$ throughout the $327-\mathrm{yr}{ }^{1 / 4^{\circ}} \mathrm{S}$ run and progressively tends to level off. 


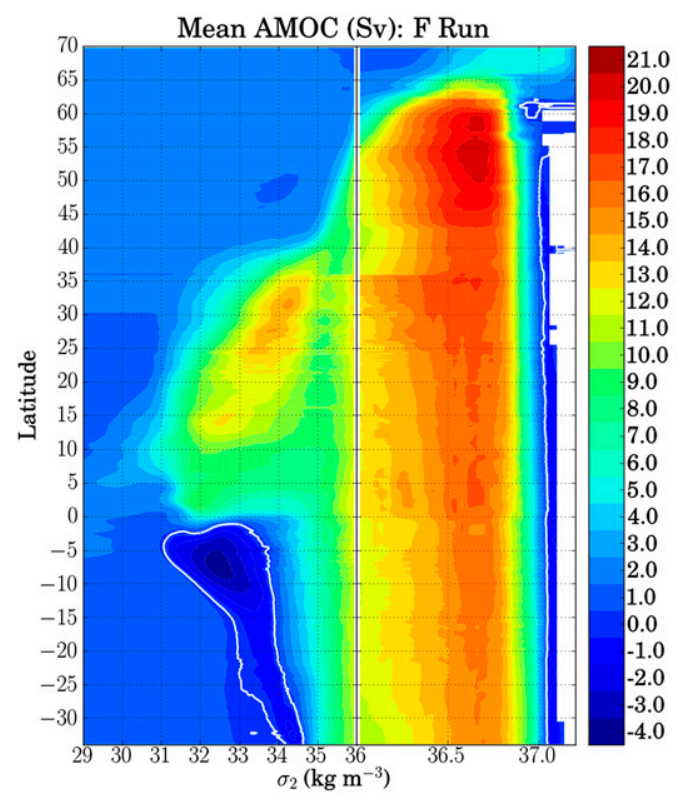

(a)



(b)

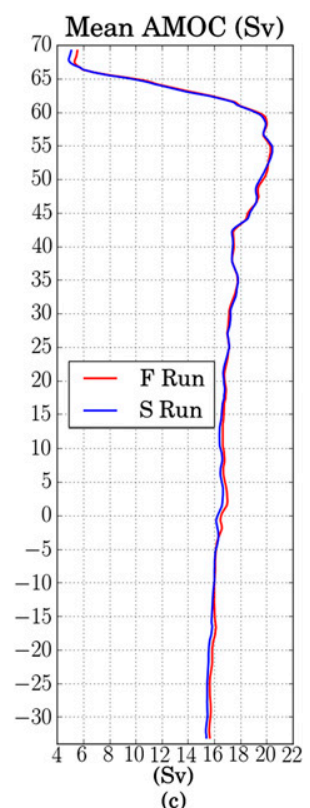

(c)

FIG. 1. Time-averaged $\mathrm{AMOC}_{\sigma_{2}}$ streamfunctions at $14^{\circ}$ (left) between 1976 and 2007 in the $\mathrm{F}$ run and (middle) between years $19-50$ in the $\mathrm{S}$ run; zero contours are shown in white. (right) The time-averaged transport of the $\mathrm{AMOC}_{\sigma_{2}}$ upper-cell northward limb in both runs (i.e., maximum of AMOC in density coordinates; refer to section 2b); a nine-point boxcar filter has been used to smooth the data.

The long-term trends found in $\mathrm{AMOC}_{z}$ and $\mathrm{AMOC}_{\sigma_{2}}$ time series in each simulation were removed at all latitudes by fitting local regression models (Loess; Cleveland et al. 1992; Cleveland and Loader 1996), which act as a nonlinear high-pass temporal filter with negligible endpoint effects. To remove signals with periods comparable to (or longer than) the length of time series, that is, to ensure proper estimates of variances and spectra, this cutoff period was set to 11 and $110 \mathrm{yr}$ for the processing of 32- and 309-yr time series, respectively (cf. red and blue lines in Fig. 2). This filtering process thus retains time scales between 2 and $11 \mathrm{yr}$ in 32-yr segments and between 2 and $110 \mathrm{yr}$ in 309 -yr segments. It is applied on all AMOC time series prior to statistical computations [standard deviation (std dev), spectra, etc.].

\section{e. Impact of temporal sampling on $\mathrm{AMOC}_{\sigma_{2}}$ variability}

As mentioned earlier, yearly $\mathrm{AMOC}_{\sigma_{2}}$ were computed from model fields archived at the monthly, "nominal" frequency. Here, we assess the possible contribution of density-velocity covariances at periods shorter than 2 months on the interannual $\mathrm{AMOC}_{\sigma_{2}}$ variability. A "reference" $\mathrm{AMOC}_{\sigma_{2}}$ time series was built from 5-day model outputs, available over the final $27 \mathrm{yr}$ of the $1 / 4^{\circ} \mathrm{S}$ run and is compared to its nominal counterpart. Figure 3 shows that the nominal $\mathrm{AMOC}_{\sigma_{2}}$ std dev is similar to its reference counterpart at most latitudes. A $\sim 15 \%$ difference, however, is found between the equator and $10^{\circ} \mathrm{N}$. Additional investigations (not shown) showed that tropical instability waves, whose typical periods are shorter than 2 months, generate a slowly varying shallow overturning cell in this latitude band; filtering this process in the AMOC computation with monthly model fields induces this $15 \%$ difference. Over most of the basin, however, our nominal dataset provides an estimate of the interannual $\mathrm{AMOC}_{\sigma_{2}}$ std dev to within a few percent.

\section{f. Intrinsic variability envelopes}

After detrending AMOC time series from all simulations at all latitudes, we computed the total std devs $s_{T}$ using the 32-yr (1976-2007) AMOC time series from F runs, and the intrinsic std devs $s_{I}$ from the nine successive 32-yr time series available in $\mathrm{S}$ runs (only two at $\left.1 / 12^{\circ}\right)$; let us note that $s_{T}, s_{I}$, and all derived quantities depend on latitude. Figure 2 indeed suggests that $s_{I}$ varies at $26^{\circ} \mathrm{N}$ during the $1 / 4^{\circ} \mathrm{S}$ run. ${ }^{3}$ At $1 / 4^{\circ}$ and $2^{\circ}$ resolutions, our best estimate of $s_{I}$ is given by the average $\overline{s_{I}}$ of these nine $s_{I}$ 's; the uncertainty of $\overline{s_{I}}$ is simply estimated by the standard deviation $s\left(s_{I}\right)$.

\footnotetext{
${ }^{3}$ Note that changes in the nine $S_{I}$ estimates are decorrelated from the long-term decrease of the original AMOC itself (Fig. 2); these changes are actually due to the presence of intrinsic variability at time scales longer than those accessible from 32-yr segments (i.e., 11 yr due to the Loess detrending).
} 


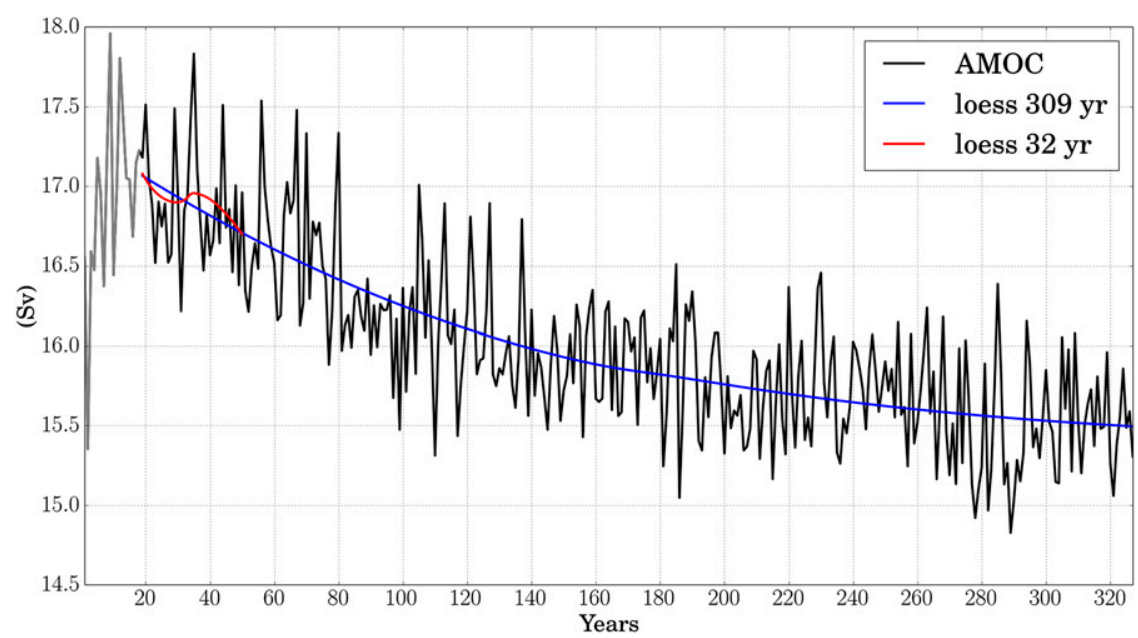

FIG. 2. Example of $\mathrm{AMOC}_{\sigma_{2}}$ raw time series (Sv; gray/black line) in the $1 / 4^{\circ} \mathrm{S}$ run over $327 \mathrm{yr}$ at the RAPID latitude $\left(26.5^{\circ} \mathrm{N}\right)$. Red and blue lines respectively represent the nonlinear (LOESS-based) trends fitted to and then removed from the 32- and 309-yr $\mathrm{AMOC}_{\sigma_{2}}$ raw time series. The first $18 \mathrm{yr}$, shown in gray, are discarded from all simulations.

The contribution of intrinsic processes to the total AMOC variance will be defined as $R=s_{I}^{2} / s_{T}^{2}$ and expressed in percent; the best estimate for this quantity is simply $\bar{R}={\overline{S_{I}}}^{2} / s_{T}^{2}$. The statistics introduced so far may also yield an accuracy estimate for $R$. Let us assume that the accuracies of $s_{T}$ and $s_{I}$ are equal, that is, $s\left(s_{T}\right)=s\left(s_{I}\right)$, and that a nine-member $s_{T}$ time series obtained from fully forced passes would be uncorrelated with our ninemember $s_{I}$ time series. This would be consistent with Hirschi et al.'s (2013) paradigm: variations in successive estimates of total AMOC std dev (with full forcing) are due to intrinsic variability, which is chaotic in nature and thus has a random phase. In that case, the uncertainty (first-order approximation) for the ratio $R$ simply reads

$$
s(R)=2 \frac{s\left(s_{I}\right)}{\overline{s_{I}}} \bar{R} \sqrt{1+\bar{R}} .
$$

The intrinsic std devs and $R$ estimates will thus be presented in terms of envelopes at $2^{\circ}$ and $1 / 4^{\circ}$, that is, will refer to $\overline{s_{I}} \pm s\left(s_{I}\right)$ and to $\bar{R} \pm s(R)$, respectively. Regarding the $1 / 12^{\circ}$ simulations, both available 32-yr estimates of $s_{I}$ and $R$ are shown for $\mathrm{AMOC}_{z}$ as a function of latitude in Fig. 7 (shown below).

MHT yearly time series were computed at each latitude from the monthly outputs of both $1 / 4^{\circ}$ simulations and nonlinearly detrended as AMOC time series. We selected the same 32-yr periods as for AMOC and calculated (one) fully forced and (nine successive) intrinsic MHT interannual variance estimates. As their equivalent $R$ for AMOC, nine $M$ ratios were calculated from these MHT variances, yielding the envelope shown in Fig. 5e and commented on in the next section.

\section{Total and intrinsic $A M O C$ variability at interannual-to-decadal time scales}

The total and intrinsic AMOC variabilities are now compared from the 32-yr time series derived from (detrended) $\mathrm{S}$ and $\mathrm{F}$ simulations, that is, over time scales

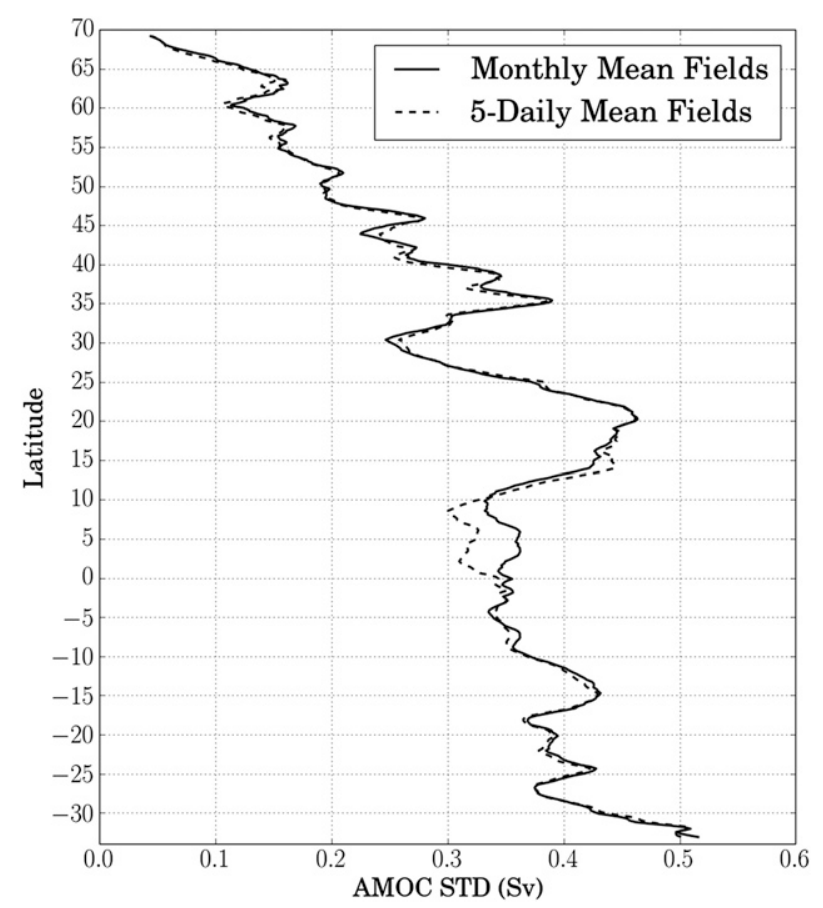

FIG. 3. $\mathrm{AMOC}_{\sigma_{2}}$ interannual std $\mathrm{dev}(\mathrm{Sv})$ computed from monthly (solid) and five daily (dashed) model fields over the last $27 \mathrm{yr}$ of the $1 / 4^{\circ} \mathrm{S}$ run. A nine-point moving average has been used to smooth the data. 


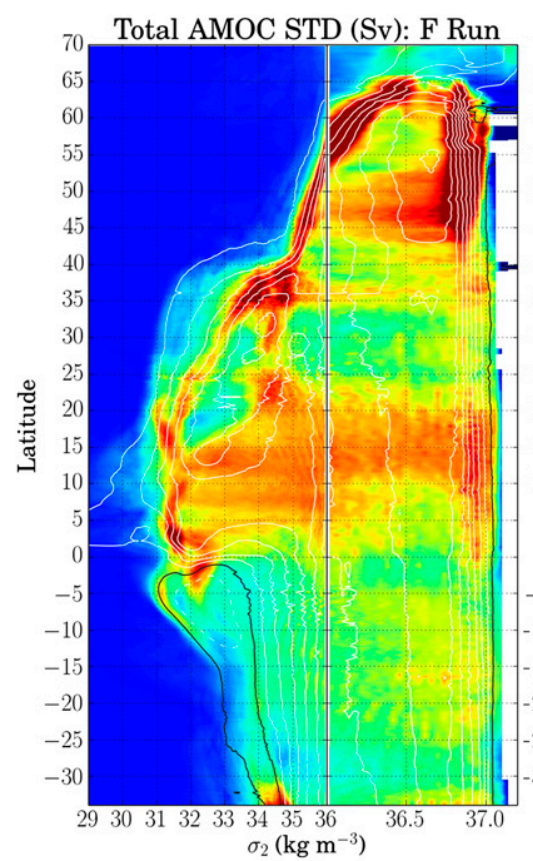

(a)

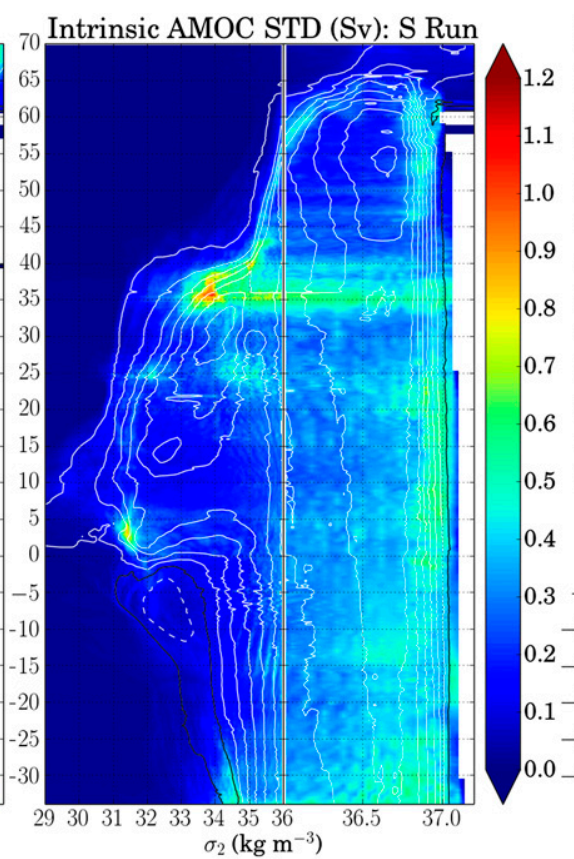

(b)



(c)

FIG. 4. (a) Total (years 1976-2007) and (b) intrinsic (years 19-50) AMOC $\sigma_{2}$ interannual std dev at $1 / 4^{\circ}$ and (c) ratio $R$ of their variances. The white contours (interval $=2.5 \mathrm{~Sv}$ ) represent the time-averaged $\mathrm{AMOC}_{\sigma_{2}}$ streamfunctions from Fig. 1; zero contours are shown in black.

ranging between 2 and $11 \mathrm{yr}$. The impact of intrinsic variability on the MHT is also examined over these 32-yr periods.

\section{a. Eddy-permitting regime $\left(14^{\circ}\right): A M O C_{\sigma_{2}}$}

Let us first compare the variability of the twodimensional $\mathrm{AMOC}_{\sigma_{2}}$ streamfunctions in the $1 / 4^{\circ}$ simulations $\mathrm{F}$ and $\mathrm{S}$ (Fig. 4). The largest AMOC variability in the $\mathrm{F}$ run (Fig. 4a), found north of $40^{\circ} \mathrm{N}$, reaches its maxima along the northward and southward limbs of this subpolar upper cell (indicated by the white contours), suggesting that the total variability affects the density of the water masses carried by both limbs. The total variability of the transport of the upper AMOC cell, that is, which may be seen in the figures around $36.7 \mathrm{~kg} \mathrm{~m}^{-3}$ where the AMOC itself is at its maximum, is smaller and only exceeds $1 \mathrm{~Sv}$ between $43^{\circ}$ and $53^{\circ} \mathrm{N}$. The subpolar intrinsic variability (Fig. 4b) exhibits a similar structure with maxima in the southward and northward limbs (density fluctuations) and weak variability of the upper-cell transport (near the AMOC maximum). Subpolar intrinsic variability is thus much weaker than its fully forced counterpart; the ratio $R$ between intrinsic and total subpolar AMOC variances remains below $10 \%$ (Fig. 4c).

One of the main peaks south of $40^{\circ} \mathrm{N}$ in fully forced and intrinsic variabilities is found around the latitude of the Gulf Stream separation $\left(35^{\circ} \mathrm{N}\right)$ across the whole density range, including the isopycnal where the AMOC itself is at its maximum; this indicates that the transport of the upper cell varies in both runs at these latitudes. Figure $4 \mathrm{c}$ shows that about half of the total interannual variability is accounted for by the intrinsic component there. The wide range of densities associated with this AMOC variability peak suggests that the associated circulation fluctuations have a barotropic character, as indeed is expected within strong recirculations observed off the U.S. coast (e.g., Bryden et al. 2009). On the other hand, our two $1 / 4^{\circ}$ simulations, like many eddy-permitting model solutions, exhibit an unrealistic, almost standing eddy near Cape Hatteras (see, e.g., Barnier et al. 2006); whether this half-intrinsic AMOC variability peak is robust and realistic is therefore questionable.

A weaker intrinsic variability peak is found near the RAPID array $\left(25^{\circ} \mathrm{N}\right)$ with a substantial contribution $(40 \%)$ to the fully forced AMOC variance. This maximum does not seem as suspicious as that mentioned above since no obvious discrepancy is found in the model solutions; the robustness of this peak at $1 / 12^{\circ}$ will be assessed in the following.

The largest fraction of intrinsic variability is found at the southern end of the domain throughout most density classes. This peak is likely to be linked to the spontaneous interannual variability in the Agulhas leakage 
(e.g., Biastoch et al. 2008). The large intrinsic fraction $R$ seen in light waters there suggest that in the upper South Atlantic the variability of the meridional circulation can only partly be predicted from surface forcing. The large surface intrinsic contribution is confined to latitudes south of $25^{\circ} \mathrm{S}$, suggesting that the variability of the horizontal surface circulation can largely be predicted from the surface forcing farther north. In deeper layers associated with the AMOC upper cell (its southward limb), the intrinsic contribution remains quite large $(30 \%-50 \%)$ between $25^{\circ} \mathrm{N}$ and the equator, which is similar to the results found for $\mathrm{AMOC}_{z}$ by Hirschi et al. (2013).

From now onward, we shall restrict our variability analyses to time series of $\mathrm{AMOC}_{\sigma_{2}}$ maxima (in density) at each latitude and each year. The time series correspond to the evolution of the strength of the northward limb of the upper AMOC cell described in the introduction. Figure 5a shows that the total $\mathrm{AMOC}_{\sigma_{2}}$ std dev in the fully forced $1 / 4^{\circ}$ simulation globally increases northward with typical values of $0.6-0.8 \mathrm{~Sv}$. It reaches its maxima in the North Atlantic Current between $45^{\circ}$ and $50^{\circ} \mathrm{N}(\sim 1.13 \mathrm{~Sv})$ and in the subtropics between $10^{\circ}$ and $20^{\circ} \mathrm{N}(\sim 0.9 \mathrm{~Sv})$. Its absolute minimum $(\sim 0.35 \mathrm{~Sv})$ lies poleward of $65^{\circ} \mathrm{N},{ }^{4}$ with three relative minima $(\sim 0.6 \mathrm{~Sv})$ within $23^{\circ}-33^{\circ} \mathrm{N}$, around the equator and south of $27^{\circ} \mathrm{S}$.

Figure $5 \mathrm{~b}$ shows the envelope of intrinsic $\mathrm{AMOC}_{\sigma_{2}}$ std dev, derived from the nine $s_{I}$ estimates computed over the successive 32-yr periods; the solid and dashed lines represent $\overline{s_{I}}, \overline{s_{I}}-s\left(s_{I}\right)$, and $\overline{s_{I}}+s\left(s_{I}\right)$ as defined in section $2 \mathrm{f}$. The dispersion $s\left(s_{I}\right)$ remains close to $10 \%-15 \%$ of its average $\overline{s_{I}}$ throughout the basin, showing a rather uniform meridional distribution of $\mathrm{AMOC}_{\sigma_{2}}$ std dev dispersion among the nine 32-yr segments of the $\mathrm{S} 1 / 4^{\circ}$ run. Switching from full to seasonal forcing (i.e., from the $\mathrm{F}$ to $\mathrm{S}$ run) reduces the interannual AMOC variance but does not suppress it, especially at the basin's southern end where the intrinsic std dev reaches $0.4 \mathrm{~Sv}$.

The contribution $R$ of intrinsic processes to the total $\mathrm{AMOC}_{\sigma_{2}}$ variance in the $1 / 4^{\circ}$ simulation is shown in Fig. $5 \mathrm{c}$ as its envelope defined in section $2 \mathrm{f}$. Roughly $15 \%-30 \%$ of the total variance $s_{T}^{2}$ happens to be due to intrinsic processes over the Atlantic tropics and subtropics, with a marked increase of $R$ from north to south. Three additional features are visible in this panel and might be relevant for the interpretation of observational MOC variability estimates. Interestingly, and despite

\footnotetext{
${ }^{4}$ A slight local maximum in $\sigma_{T}$ may, however, be seen along the $36.7 \mathrm{~kg} \mathrm{~m}^{-3}$ isopycnal in Fig. 4a near this latitude; this difference is explained by temporal changes in isopycnals along which $\mathrm{AMOC}_{\sigma_{2}}$ reaches its successive maxima, which are in turn used in Fig. 5a.
}

substantial differences in experimental strategies and model setups, the three following features are also visible in Hirschi et al. (2013):

- $R$ reaches its absolute maximum $(50 \% \pm 15 \%)$ around $30^{\circ} \mathrm{S}$. This latitude sits a few degrees north of the SAMOC monitoring array, which is currently being deployed at $34.5^{\circ} \mathrm{S}$ and where $R$ remains substantial $(40 \% \pm 10 \%)$. There, a substantial part of the interannual AMOC variability may not be directly related to that of the atmosphere and purely due to oceanic processes.

- Between $24^{\circ}$ and $26^{\circ} \mathrm{N}$, the total and intrinsic $\mathrm{AMOC}_{\sigma_{2}}$ variabilities reach a local minimum and maximum, respectively; $R$ reaches its secondary maximum $(40 \% \pm 10 \%)$ at $25^{\circ} \mathrm{N}$, and $R=30 \% \pm 10 \%$ at the latitude of the RAPID array. Whether this result is robust to other model parameters remains to be seen, but these results suggest that interannual AMOC variability measured at $26.5^{\circ} \mathrm{N}$ may be affected by ocean-driven processes.

- As expected from the opposite basin-scale gradients of total and intrinsic std dev's, intrinsic processes reach their minimum contribution $(\sim 5 \%)$ between $45^{\circ}$ and $60^{\circ} \mathrm{N}$. This subpolar area almost entirely encompasses the paths of OVIDE tracks along which several observational $\mathrm{AMOC}_{\sigma_{1}}$ estimates have been derived since 2002 (Treguier et al. 2006; Mercier et al. 2013). The forthcoming OSNAP monitoring array will also be deployed within this gyre. Despite the misalignment between nonzonal OVIDE tracks and our quasizonal model grid there, and despite the difference in density reference levels, our results suggest that in this area almost all the interannual-to-decadal AMOC variance is related to the atmosphere with a minor contribution of oceanic processes. Interestingly, $R$ at $1 / 4^{\circ}$ reaches a localized maximum around $65^{\circ} \mathrm{N}$ (near the Greenland-Iceland-Scotland Ridge), where the total variability $s_{T}^{2}$ reaches a minimum. A local $R$ maximum is found right above this ridge in our $1 / 12^{\circ}$ experiments as well ( $R \sim 23 \%$, Fig. 6). This topographic feature may therefore host oceanic processes in our $1 / 4^{\circ}$ and $1 / 12^{\circ}$ simulations that locally increase $R$, that is, processes that moderate the strong connection between the atmosphere and interannual AMOC variance.

The interannual intrinsic variabilities of $\mathrm{AMOC}_{\sigma_{2}}$ and MHT are significantly correlated across a wide range of latitudes over the nine successive 32 -yr periods of the $1 / 4^{\circ}$ S run (Fig. 5d); $50 \%-74 \%$ of the MHT and $\mathrm{AMOC}_{\sigma_{2}}$ intrinsic variances are shared between $34^{\circ}$ and $5^{\circ} \mathrm{S}, 18^{\circ}$ and $43^{\circ} \mathrm{N}$, and $45^{\circ}$ and $54^{\circ} \mathrm{N}$. The intrinsic MHT and $\mathrm{AMOC}_{\sigma_{2}}$ variabilities have comparable meridional 




(a)



(b)



(d)

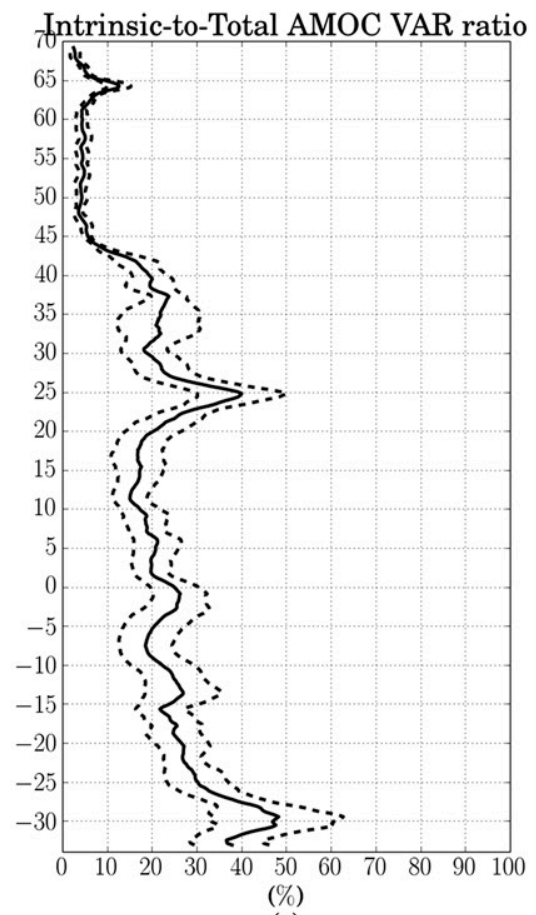

(c)

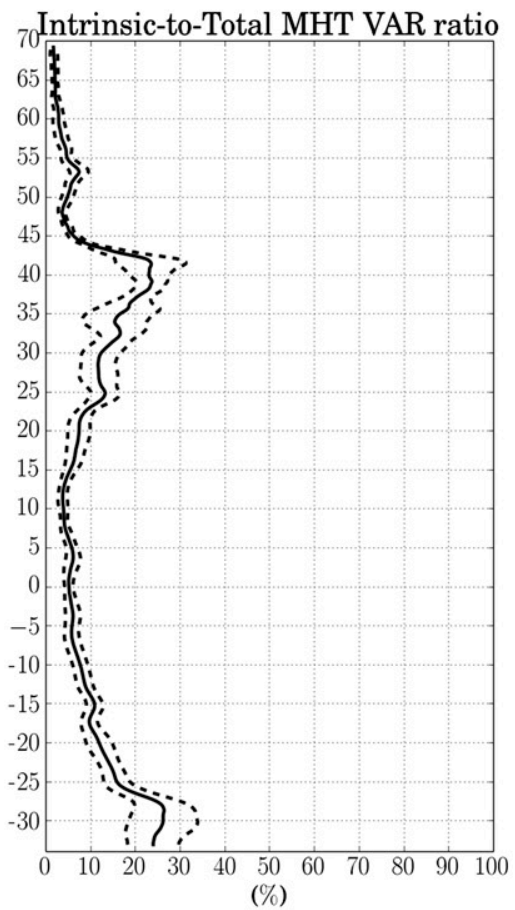

(e)

FIG. 5. (a) Total and (b) intrinsic interannual standard deviations of the $\mathrm{AMOC}_{\sigma_{2}}$ upper-cell northward limb transports at $1 / 4^{\circ}$, and (c) the ratio $R$ of their variances. The nine successive $32-\mathrm{yr} s_{I}$ estimates of intrinsic variability are shown in gray in (b). The solid and dashed black lines in (b) and (c) represent the averages and envelopes of the nine $s_{I}$ estimates presented in section 2f. (d) Correlation between intrinsic interannual $\mathrm{AMOC}_{\sigma_{2}}$ and $\mathrm{MHT}$ variabilities at $1 / 4^{\circ}$ over the nine successive 32 -yr periods. Solid and dashed lines represent the mean and std dev of the correlation coefficient over the nine periods, respectively. Thick solid lines show where the correlations remain significant throughout the nine periods. (e) As in (c), but for the interannual MHT at $1 / 4^{\circ}$ (envelope of $M$ defined in section $2 \mathrm{f}$ ). A ninepoint moving average has been used to smooth these data. 


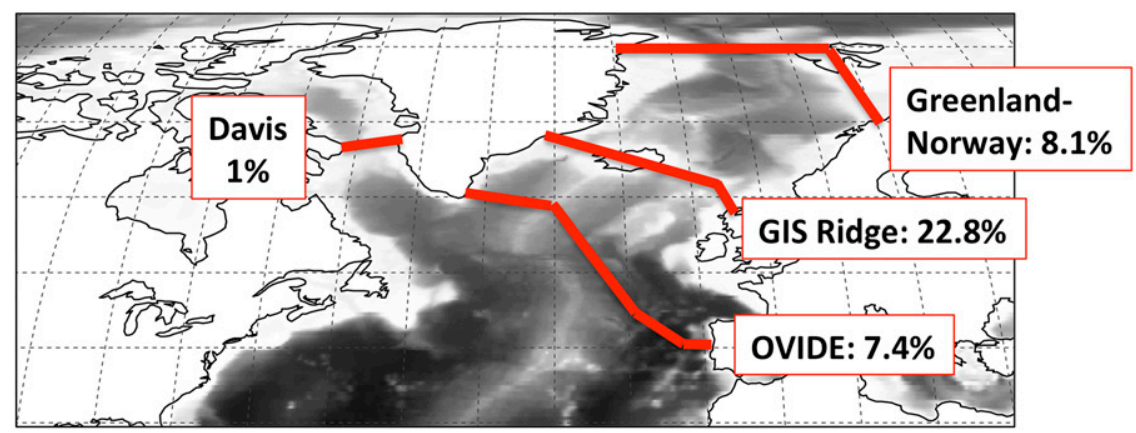

FIG. 6. Intrinsic-to-total $\mathrm{LF}$ variance ratio $R$ from $\mathrm{AMOC}_{\sigma_{2}}$ time series computed across four sections from our $1 / 12^{\circ}$ simulations. The shaded background shows topography.

distributions (not shown) at these latitude ranges. The ratio $M$ between intrinsic and total MHT variances (its envelope is shown in Fig. 5e) is substantial in the South Atlantic, as was noted for $R$; $M$ reaches its absolute maximum $(\sim 26 \% \pm 7 \%)$ near the SAMOC latitude around $30^{\circ} \mathrm{S}$. Between $15^{\circ} \mathrm{S}$ and $23^{\circ} \mathrm{N}$, intrinsic processes contribute to less than $10 \%$ of the MHT variance because of a marked maximum of the fully forced MHT variability (not shown). The term $M$ reaches $\sim 12 \% \pm$ $3 \%$ at RAPID $\left(26.5^{\circ} \mathrm{N}\right)$ and $\sim 23 \% \pm 6 \%$ in the Gulf Stream extension $\left(37^{\circ}-42^{\circ} \mathrm{N}\right)$. As for $\mathrm{AMOC}_{\sigma_{2}}$, the contribution of intrinsic processes to the total MHT variance reaches its absolute minimum north of $45^{\circ} \mathrm{N}$, where OVIDE and OSNAP measurements have and will be made. The interannual variability of the northward heat transport is therefore mostly controlled by the atmosphere in the subpolar gyre but is partly due to intrinsic processes at midlatitudes.

\section{b. Laminar, eddy-permitting, and eddy-resolving regimes: $A M O C_{z}$}

As explained earlier, we switch from $\mathrm{AMOC}_{\sigma_{2}}$ to $\mathrm{AMOC}_{z}$ within this section. Let us first investigate how this switch affects overturning variabilities by comparing Figs. 5a and $7 \mathrm{a}$ in terms of total std dev's at $1 / 4^{\circ}$ (black lines). The total standard deviations of both quantities at $1 / 4^{\circ}$ are very close to each other south of $40^{\circ} \mathrm{N}$, a result similar to that reported by Zhang (2010, her Fig. 2b) in the laminar regime. Poleward of $40^{\circ} \mathrm{N}$, however, std devs are systematically larger in terms of $\mathrm{AMOC}_{\sigma_{2}}$ than of $\mathrm{AMOC}_{z}$. This reflects the fact that $\mathrm{AMOC}_{\sigma_{2}}$ variabilities integrate both the zonally integrated vertically accumulated transport and the horizontal gyre circulation and that the contribution of this latter component increases toward subpolar latitudes (e.g., Marsh et al. 2009). These authors also reported stronger $\mathrm{AMOC}_{z}$ values at subpolar latitudes in coarse-resolution simulations, as most of the meridional transports occur in the overturning part in laminar regimes but are more evenly split between gyre and overturning parts in eddying regimes. This resolution impact is confirmed by our results in terms of interannual variability (stronger at $2^{\circ}$, red line in Fig. 7a).

We now investigate how the model resolution influences intrinsic variability. Figure $7 \mathrm{~b}$ demonstrates that switching from the eddy-permitting $\left(1 / 4^{\circ}\right)$ to laminar regime $\left(2^{\circ}\right)$ almost entirely suppresses interannual intrinsic variability of $\mathrm{AMOC}_{z}$, as it does for the sea level (Penduff et al. 2011). The basin's intrinsic variability minimum is found north of $40^{\circ} \mathrm{N}$ both at $1 / 4^{\circ}$ and $1 / 12^{\circ}$ but is stronger in the latter case. At least in this subpolar region, the intensity of interannual intrinsic variability therefore seems to increase with the ability of the model to (even partly) resolve mesoscale eddies. Figure 5a indicates that this does not imply that the total AMOC std dev increases under full forcing when switching from $1 / 4^{\circ}$ to $1 / 12^{\circ}$ resolution. Interestingly, the $1 / 4^{\circ}-1 / 12^{\circ}$ resolution increase barely changes the general distribution and magnitude of this intrinsic std dev between $35^{\circ} \mathrm{S}$ and $40^{\circ} \mathrm{N}$; over most of this latitude range the two estimates of intrinsic std dev at $1 / 12^{\circ}$ remain within (or very close to) the $1 / 4^{\circ}$ envelope. Figure $7 b$ shows that in both eddying simulations, the strongest imprint of LF intrinsic variability on $\mathrm{AMOC}_{z}$ occurs around the latitude of the Gulf Stream; substantial and relatively uniform $\sigma_{I}$ levels are then found between this latitude and $35^{\circ} \mathrm{S}$. This meridional distribution is in contrast with the imprint of LF intrinsic variability on sea surface height (SSH) at both $1 / 4^{\circ}$ and $1 / 12^{\circ}$ (see Penduff et al. 2011; Sérazin et al. 2015), which exhibits very distinct peaks in the highly turbulent Gulf Stream and Agulhas retroflection regions, with almost no SSH imprint in between. Both the horizontal and overturning circulations are thus impacted by LF intrinsic variability in these two eddyactive regions. Its relatively uniform imprint on AMOC between these latitudes is likely related to the marked meridional coherence of AMOC intrinsic variability anomalies across this latitude range at 


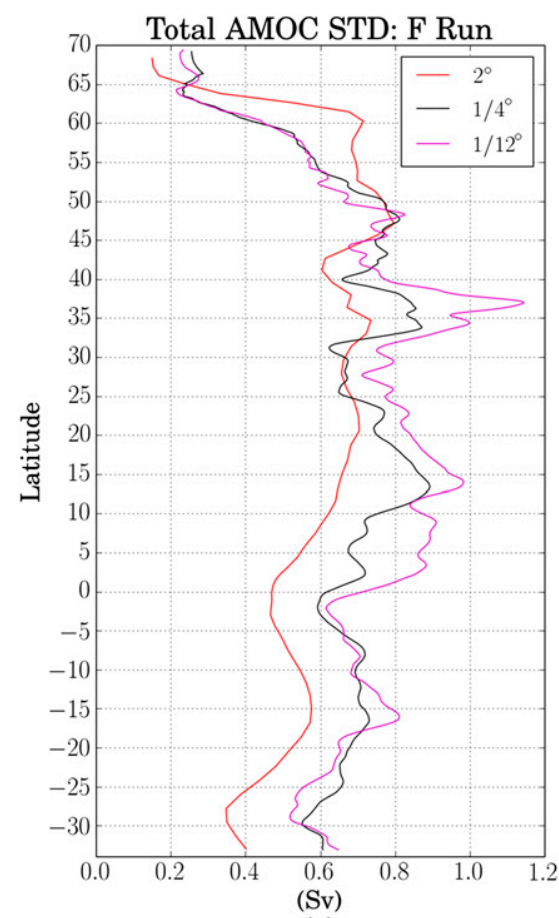

(a)

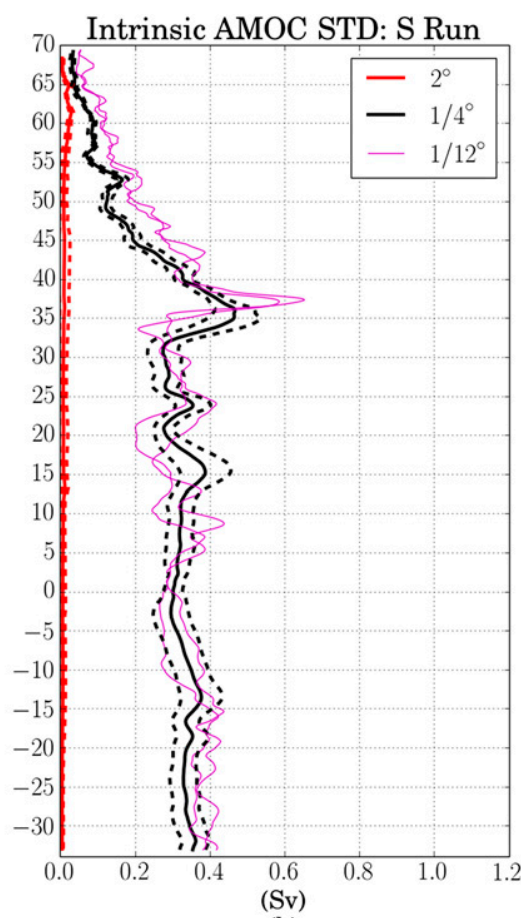

(b)

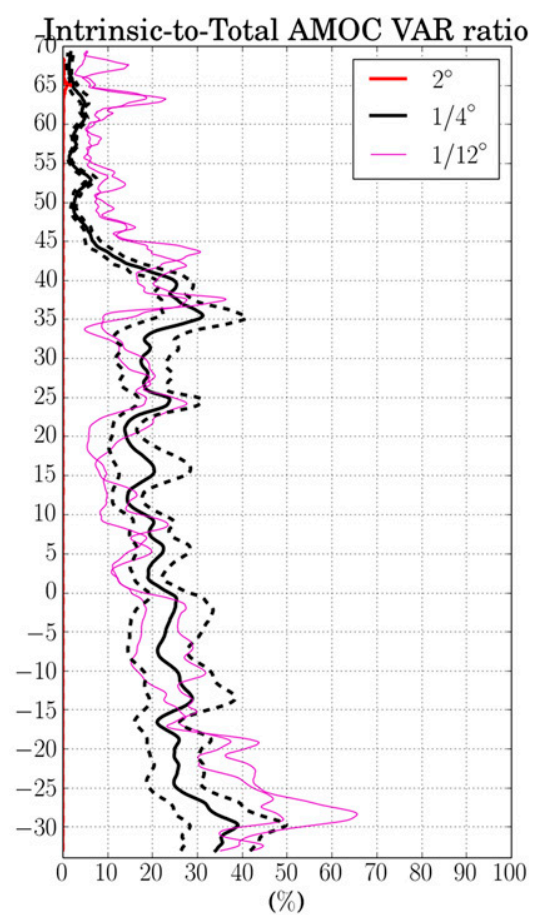

(c)

FIG. 7. As in Fig. 5, but for $\mathrm{AMOC}_{z}$ at $14^{\circ}, 2^{\circ}$, and $1 / 12^{\circ}$. (b) Two intrinsic std devs and (c) $R$ at $1 / 12^{\circ}$ resolution are computed from the two 32 -yr segments available in the $\mathrm{S}$ run. The 9 - and 25 -point moving averages were used to smooth the $1 / 4^{\circ}$ and $1 / 12^{\circ}$ results, respectively.

interannual-to-decadal periods (as discussed in section $4 \mathrm{~d}$ for longer time scales).

Figure 7c summarizes the impact of resolution on $R$, the intrinsic-to-total interannual variance ratio. The interannual variability of the forcing explains nearly all interannual $\mathrm{AMOC}_{z}$ variance at $2^{\circ}$ throughout the basin and remains largely dominant (up to $95 \%$ ) in the subpolar gyre when eddies are present $\left(1 / 4^{\circ}\right.$ and $\left.1 / 12^{\circ}\right)$. In both eddying simulations, however, the contribution of nonlinear intrinsic processes in the total AMOC variance tends to increase toward the south and reaches about one-third around $35^{\circ} \mathrm{N}$ up to $40 \%-50 \%$ in the Agulhas region. Our comments about the $R$ extrema found at OVIDE and SAMOC in terms of $\mathrm{AMOC}_{\sigma_{2}}$ (previous section) thus remain valid in terms of $\mathrm{AMOC}_{z}$, but $R$ is smaller at RAPID $(20 \% \pm 5 \%)$ than in terms of $\mathrm{AMOC}_{\sigma_{2}}$; intrinsic variability here is partly associated with meridional flows occurring at different densities but same depths.

Thomas and Zhai (2013) used a different model (MITgcm), resolution $\left(1 / 10^{\circ}\right)$, and experimental strategy, but comparing our Fig. $7 \mathrm{c}$ with the black line in their Fig. 4 is instructive. First, their estimate of the $R$ ratio in the eddying regime compares quite well with ours in the $20^{\circ}-45^{\circ} \mathrm{N}$ latitude range (and with our $1 / 12^{\circ}$ results at subpolar latitudes). Second, this comparison strongly suggests that most of the intrinsic interannual variability in the northern tropics $\left(0^{\circ}-20^{\circ} \mathrm{N}\right)$ comes from the southern basin. Indeed, their use of a closed southern boundary at $14^{\circ} \mathrm{S}$ yields a negligible intrinsic interannual variability at low latitudes, while it remains substantial and homogeneous across $34^{\circ} \mathrm{S}-30^{\circ} \mathrm{N}$ in our global configurations as well as in Hirschi et al.'s (2013). This result is also consistent with Biastoch et al. (2008) who showed how intrinsic AMOC variability generated in the turbulent Agulhas region can influence the tropical North Atlantic.

Interestingly, our $1 / 4^{\circ}$ model proves able to capture the essential processes generating intrinsic variability since $1 / 12^{\circ}$ and $1 / 4^{\circ}$ results do not differ much from each other, at least south of the subpolar gyre. Most of our results there are also robust to the use of $\mathrm{AMOC}_{z}$ or $\mathrm{AMOC}_{\sigma_{2}}$.

\section{Long-term $\mathrm{AMOC}_{\sigma_{2}}$ intrinsic variability at $1 / 4^{\circ}$}

We now take advantage of the 327-yr seasonally forced $1 / 4^{\circ}$ simulation to describe the long-term evolution of the intrinsic $\mathrm{AMOC}_{\sigma_{2}}$ variability. (i) We first highlight its general features through a time-frequency analysis at four selected latitudes; (ii) we then focus on the evolution of interannual-to-decadal intrinsic variability, and (iii) its possible relationship with the atmospheric variability, and (iv) focus on the time-latitude 

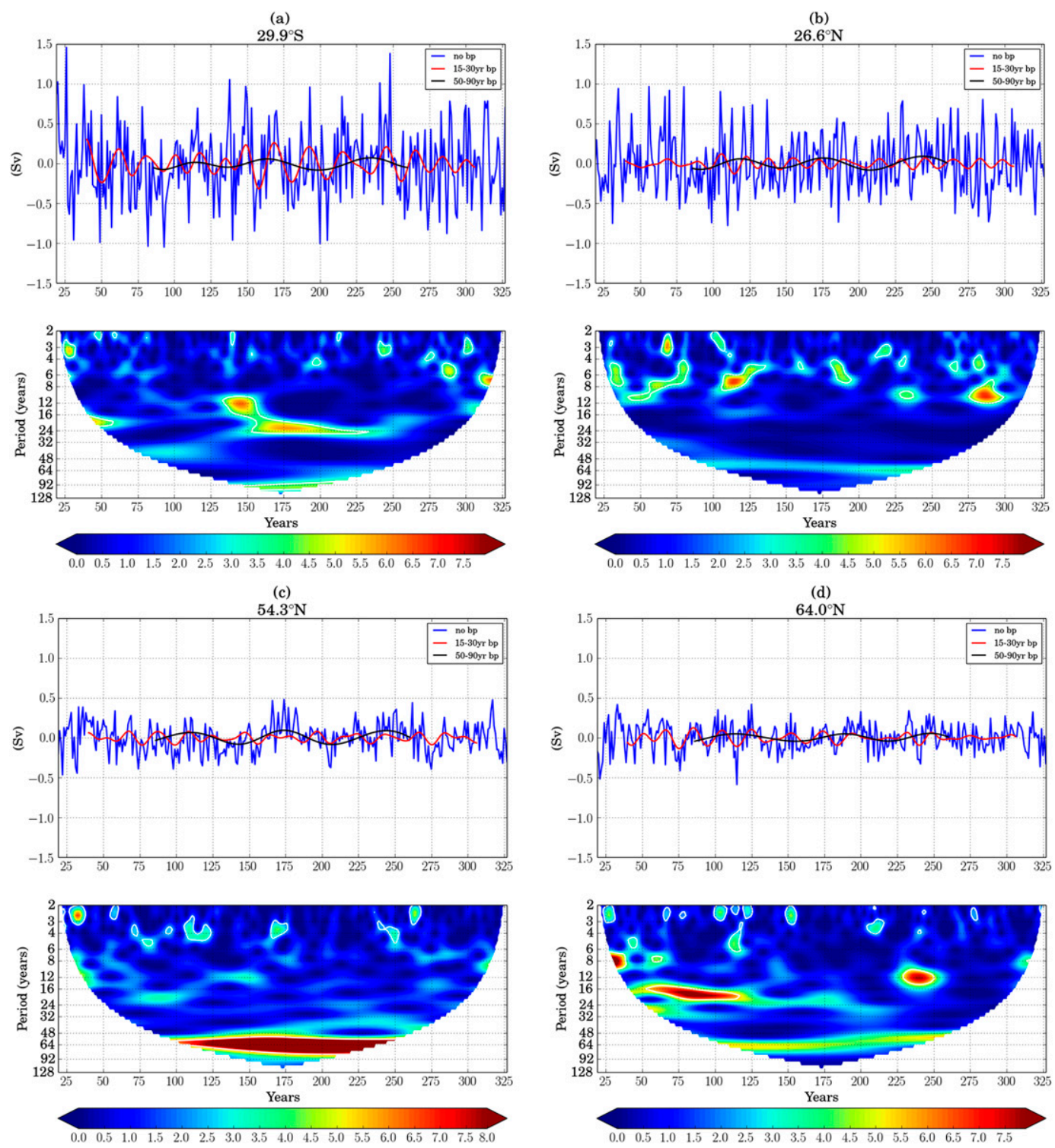

FIG. 8. Intrinsic $\mathrm{AMOC}_{\sigma_{2}}$ anomaly time series and wavelet power spectra from the last $309 \mathrm{yr}$ of the $1 / 4^{\circ} \mathrm{S}$ run at (a) $29.9^{\circ} \mathrm{S}$, (b) $26.6^{\circ} \mathrm{N}$, (c) $54.3^{\circ} \mathrm{N}$, and (d) $64^{\circ} \mathrm{N}$. Shown are unfiltered (blue) and bandpass-filtered yearly time series in the 15-30- (red) and 50-90-yr (black) bands, for comparison with Fig. 10. Wavelet spectra are normalized by the variance of time series; white contours indicate $95 \%$ confidence levels.

distribution of the multidecadal intrinsic variability throughout the basin.

\section{a. Time-frequency analysis of the intrinsic variability}

Detrended 309-yr time series of intrinsic $\mathrm{AMOC}_{\sigma_{2}}$ anomalies are presented at four latitudes in Fig. 8, along with corresponding wavelet power spectra. Morlet wavelets (see Torrence and Compo 1998) were chosen, spectra were normalized by $\mathrm{AMOC}_{\sigma_{2}} \mathrm{LF}$ variances, and confidence levels, shown as contours, were obtained by fitting lag- 1 autoregressive red noise processes. The four chosen latitudes correspond to the observational arrays mentioned earlier and/or to intrinsic $\mathrm{AMOC}_{\sigma_{2}}$ extrema visible in Fig. 5; both $R$ maxima found at SAMOC and RAPID (Figs. 8a,b), the $R$ minimum around OVIDE (Fig. 8c), and the $R$ maximum above the GreenlandIceland-Scotland Ridge (Fig. 8d).

The main feature visible in these wavelet spectra (and at other latitudes as well) is the temporal irregularity of the frequency content throughout the $14^{\circ} \mathrm{S}$ run. Significant spectral peaks appear and disappear during the run; these occurrences are not particularly confined at the 
beginning or the end of the simulation, suggesting that the long-term adjustment of the model state does not adversely contaminate these results. The wavelet transforms also show that this intrinsic $\mathrm{AMOC}_{\sigma_{2}}$ variability concerns a wide frequency range, with significant power at interannual-to-decadal time scales throughout the Atlantic.

\section{b. Interannual-to-decadal intrinsic variability}

$\mathrm{AMOC}_{\sigma_{2}}$ Fourier spectra are computed at each latitude over the nine successive $32-\mathrm{yr}$ segments of the $1 / 4^{\circ} \mathrm{S}$ run (left panels in Fig. 9). Confidence levels are estimated as in Torrence and Compo (1998) by modeling background spectra as red noise (lag-1 autoregressive process). These panels reveal generic features of the intrinsic variability that persist throughout the simulation; at low and midlatitudes, significant spectral peaks are visible most of the time, extending over wide (up to $30^{\circ} \mathrm{N}$ ) latitudinal ranges at well-defined frequencies. These "ridges" are particularly clear south of $25^{\circ} \mathrm{N}$; several of them happen to span the whole South Atlantic at about 3-, 5-, and 8-yr periods. Comparable structures also appear in the northern subtropics, with somewhat shorter meridional extents though. North of about $40^{\circ} \mathrm{N}$, intrinsic variability has a reduced contribution to the AMOC variance; its frequency peaks are more confined in latitude and fluctuate more in time.

These results are summarized in color in the lowerright panel of Fig. 9, which shows the probability that intrinsic variability reaches a significant spectral peak during these nine periods. Everywhere south of about $25^{\circ} \mathrm{N}$, intrinsic $\mathrm{AMOC}_{\sigma_{2}}$ variability often occurs $(30 \%-$ $50 \%$ of the $309-\mathrm{yr}$ period) at 8 - and 4.5 -yr periods; additional occurrences are detected around $3 \mathrm{yr}$ in the South Atlantic, suggesting that future SAMOC measurements may include intrinsic AMOC signals around these three interannual peaks. Between $25^{\circ}$ and $40^{\circ} \mathrm{N}$, significant spectral peaks are mostly found around 56 yr. More detailed investigations in our $1 / 4^{\circ}$ and $1 / 12^{\circ} \mathrm{S}$ runs confirm that AMOC at the RAPID array $\left(26.5^{\circ} \mathrm{N}\right)$ has intrinsic variability peaks near $4-5$ and $10 \mathrm{yr}$. This variability is in line with Rossby wave-like intrinsic modes that continuously cross the basin between $15^{\circ}$ and $35^{\circ} \mathrm{N}$ (see Penduff et al. 2011, their section 4.a.2) in both simulations and whose spatiotemporal features are very similar to those found by Hazeleger and Drijfhout (2000) in idealized simulations.

Significant peaks occur at more diverse periods farther north; however, intrinsic variability seems to preferably peak around 3.5 and $8 \mathrm{yr}$ poleward of $45^{\circ} \mathrm{N}$, with slightly longer periods ( 5 and $10 \mathrm{yr}$ ) at the northern boundary of the basin. In summary, the amplitude, latitudinal extent, and dominant frequencies of intrinsic
$\mathrm{AMOC}_{\sigma_{2}}$ variability vary in a substantial, complex, and intermittent way during the integration, as expected from the irregular shape of the wavelets (Fig. 8).

The impact of model resolution on interannual intrinsic variability spectra is difficult to assess accurately. $\mathrm{AMOC}_{z}$ intrinsic variability spectra at $1 / 12^{\circ}$ are indeed available over two 32-yr periods only (not shown) and are quite different from each other (as in the $1 / 4^{\circ}$ case, see Fig. 9). Although the intensity of intrinsic variability is similar over these successive periods (Fig. 7b), no robust estimate of the $1 / 12^{\circ}$ intrinsic variability spectral peaks may be derived from these two realizations. However, meridionally coherent spectral peaks appear between about $35^{\circ} \mathrm{S}$ and $35^{\circ} \mathrm{N}$ at both resolutions and over many 32-yr periods of the $\mathrm{S}$ runs, suggesting that this feature of intrinsic variability is robust.

\section{c. Possible impacts of the atmospheric forcing}

The spectrum of $\mathrm{AMOC}_{\sigma_{2}}$ variability was also computed over $1976-2007$ from the fully forced $1 / 4^{\circ}$ run; its significant peaks are superimposed in white in the lowerright panel of Fig. 9 in order to assess potential correspondences between AMOC preferred periods, with and without interannual forcing. Interestingly, both simulations exhibit common spectral peaks in a few regions: around 5-6yr at the northern limit of the basin $\left(68^{\circ}-70^{\circ} \mathrm{N}\right)$ as well as around $30^{\circ}-40^{\circ} \mathrm{N}$. Gulf Stream surface velocity observations (Ezer et al. 2013) confirm the actual existence of this latter peak, which might therefore be of intrinsic origin. Correspondence between seasonally and fully forced AMOC spectral peaks is less clear but may also be present in the subpolar gyre, around $8 \mathrm{yr}$ between $45^{\circ}$ and $60^{\circ} \mathrm{N}$; this peak could therefore be of intrinsic origin but also may be excited by the North Atlantic Oscillation (NAO; see Eden and Willebrand 2001). In this region, we may hypothesize that the interannual forcing excites and paces intrinsic variability modes that spontaneously emerge in the $\mathrm{S}$ run. A similar paradigm was proposed by Pierini (2014) in the Kuroshio, but assessing its relevance in the present case would require further investigations.

At lower latitudes, white contours reveal that switching on the interannual forcing does not affect the meridional alignment of spectral peaks. This feature was clearly noticed in the S run, strongly suggesting that the meridional coherence of the forced (and observed) interannual-to-decadal AMOC variability is inherent in oceanic dynamics. These intrinsic and fully forced spectral peaks, however, are found at different periods at mid- and low latitudes. Whether these correspondences and differences in AMOC variability peaks are realistic and robust is unclear; an ensemble of simulations (e.g., different resolutions, initial conditions, and 



FIG. 9. (left) Frequency-latitude Fourier power spectra of the intrinsic $\mathrm{AMOC}_{\sigma_{2}}$ variability during the nine successive 32 -yr periods of the $1 / 4^{\circ} \mathrm{S}$ run. Spectra are normalized by the $\mathrm{AMOC}_{\sigma_{2}}$ interannual variance at each latitude. Black and white contour lines indicate $95 \%$ and $90 \%$ confidence levels, respectively. (bottom right) Probability that these intrinsic variability peaks are significant at $90 \%$ over the nine periods (color, refer to section $4 \mathrm{~b}$ ); regions of the frequency-latitude plane where total variability spectral peaks in the fully forced $1 / 4^{\circ} \mathrm{F}$ run are significant at $90 \%$ (black contours, refer to section $4 \mathrm{c}$ ). Dashed white/black line shows the cutoff period of the Loess detrending operator. 
(a) 15-30 year bandpass filtered intrinsic $\mathrm{AMOC}_{\alpha_{2}}$

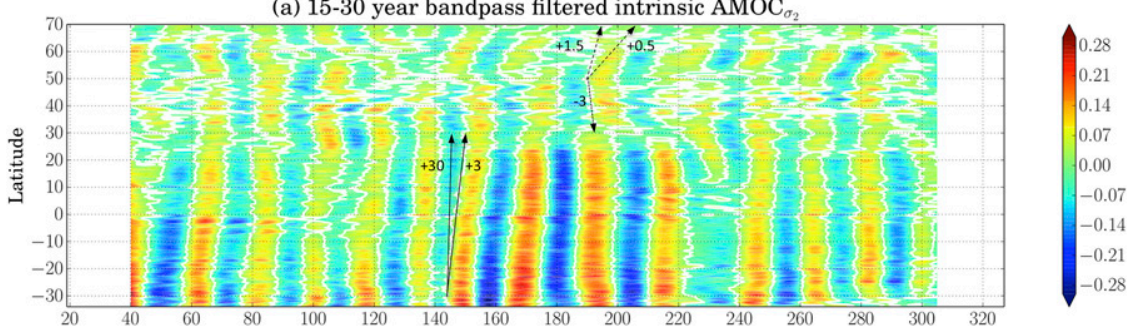

(b) 50-90 year bandpass filtered intrinsic $\mathrm{AMOC}_{\sigma_{2}}$

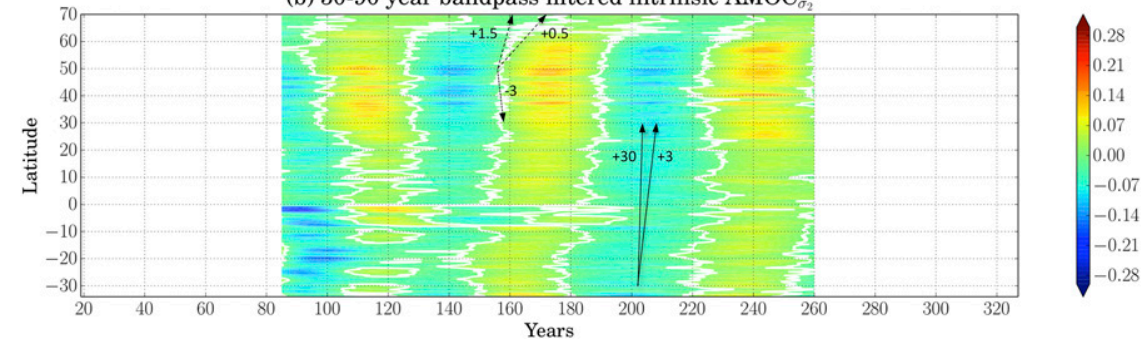

FIG. 10. Time-latitude plots of intrinsic $\mathrm{AMOC}_{\sigma_{2}}$ anomalies (Sv) during the $1 / 4^{\circ} \mathrm{S}$ run, bandpass filtered (top) in the 15-30-yr band and (bottom) in the 50-90-yr band; initial and final parts of the time series are ignored because of the side effects of the Lanczos filters. Slanted lines and associated numbers indicate ranges of meridional phase speeds $\left(\mathrm{cm} \mathrm{s}^{-1}\right)$ that dominate within selected latitude ranges; pluses and minuses correspond to northward and southward propagation, respectively.

parameters) would be necessary to assess whether AMOC variability periods are biased in our $\mathrm{S}$ run and may better match their fully forced counterparts or if the fully forced periods would be the same in different conditions. On the other hand, frequency shifts due to the forcing are known to exist in nonlinear systems like the eddying ocean (e.g., Kartashova 2011), and such effects might also explain these differences. These assessments are left for future studies.

\section{d. Multidecadal intrinsic variability}

Wavelet power spectra (Fig. 8) have shown that intrinsic $\mathrm{AMOC}_{\sigma_{2}}$ variability in the $1 / 4^{\circ} \mathrm{S}$ run can also be significant at multidecadal periods: $15-30 \mathrm{yr}$ at $64^{\circ} \mathrm{N}$ and $30^{\circ} \mathrm{S}$ and up to $50-90 \mathrm{yr}$ at $54.3^{\circ} \mathrm{N}$ and $30^{\circ} \mathrm{S}$ (Figs. $8 \mathrm{a}, \mathrm{c}, \mathrm{d}$ ). Multidecadal peaks are intermittently visible at other latitudes as well, but they do not appear as significant in Fig. 8, perhaps masked by more energetic, simultaneous, shorter-period signals. To highlight the meridionaltemporal structure of these multidecadal signals, intrinsic $\mathrm{AMOC}_{\sigma_{2}}$ time series were bandpass filtered at each latitude using a temporal Lanczos filter in the 15 30- and 50-90-yr bands (see Fig. 10); these plots reveal that these intermittent multidecadal oscillations have a substantial coherence over large meridional extents.

The 15-30-yr intrinsic AMOC anomalies are strongest at the southern end of the domain. They extend over the whole South Atlantic (e.g., years 50-80 in the top panel) and often reach the RAPID latitude without much attenuation (see at $26^{\circ} \mathrm{N}$, middle of the top panel), with occasional extensions farther north. In contrast, the 5090-yr intrinsic AMOC anomalies tend to be strongest in the $30^{\circ}-60^{\circ} \mathrm{N}$ latitudinal band. Hovmoeller diagrams in both frequency bands show that most AMOC intrinsic anomalies propagate in latitude but at phase speeds that happen to vary in space and time and with occasional changes in direction. South of $30^{\circ} \mathrm{N}$ for instance, most anomalies propagate northward, with an acceleration of phase speeds (phase lines are closer to the vertical) after year 210 in the 15-30-yr band or even a tendency for southward propagation before year 130 in the 50-90-yr band. Despite these features, which further illustrate the nonstationary character of intrinsic variability, most AMOC signals in this $30^{\circ} \mathrm{S}-30^{\circ} \mathrm{N}$ latitude band propagate northward in both frequency bands with phase speeds lying within the range $3-30 \mathrm{~cm} \mathrm{~s}^{-1}$, as reported by Biastoch et al. (2008) at shorter (decadal) time scales.

The coherence of AMOC anomalies in the 15-30-yr band is somewhat blurred by meridionally confined disturbances in the $30^{\circ}-50^{\circ} \mathrm{N}$ latitudinal range but remains much clearer in the 50-90-yr band. Interestingly, most intrinsic AMOC anomalies seem to propagate southward from $50^{\circ}$ to $30^{\circ} \mathrm{N}$ in this intergyre region, in particular in the 50-90-yr band (at about $3 \mathrm{~cm} \mathrm{~s}^{-1}$ ) and in the $15-30-y r$ band between years 120 and 260. North of $50^{\circ} \mathrm{N}$ in the subpolar gyre, meridional propagation of AMOC anomalies remains dominantly northward in both frequency bands (also in the 6-15 and 30-50-yr 
bands, not shown); these phase speeds are smaller (0.5$1.5 \mathrm{~cm} \mathrm{~s}^{-1}$ ) at these high latitudes and may be related to the poleward advection of anomalous isopycnal transports across the eastern North Atlantic. A number of intrinsic AMOC anomalies thus have an approximate C-shaped pattern north of $30^{\circ} \mathrm{N}$ at these multidecadal scales (as well as in the 30-50-yr period range, not shown) and seem to propagate away from the $50^{\circ} \mathrm{N}$ latitude line. Whether this feature is also found in other OGCM simulations needs to be verified. Simplified model simulations would then help identify the possible source of these signals, which approximately lies at the latitude where the North Atlantic Current crosses the basin. More generally, explaining the nonlinear dynamics that are likely to generate and propagate these superimposed, nonstationary, and complex multidecadal signals lies beyond the scope of this study and is left for future process-oriented investigations.

\section{Conclusions and discussion}

Three global ocean-sea ice model simulations, forced at the surface by a repeated annual cycle, have been analyzed in terms of AMOC intrinsic variability at interannual-to-multidecadal time scales. Intrinsic variability emerges spontaneously at these time scales when mesoscale eddies are (even partly) resolved, that is, in our $1 / 4^{\circ}$ and $1 / 12^{\circ}$ resolution models. At $2^{\circ}$ resolution, the same model does not produce any low frequency spontaneously. Equatorward of $40^{\circ} \mathrm{N}$, the intrinsic AMOC low-frequency variance $s_{I}^{2}$ does not significantly increase when switching from $1 / 4^{\circ}$ to $1 / 12^{\circ}$ resolution, suggesting that its dynamical sources are properly simulated at low and midlatitudes in the eddy-permitting regime.

The same three model configurations were also driven over the last decades by a forcing based on atmospheric reanalyses that now include interannual and longer time scales. These fully forced hindcasts yield estimates at three resolutions of the "total" interannual-to-decadal AMOC variability, which was compared to its intrinsic counterpart. At $1 / 4^{\circ}$ and $1 / 12^{\circ}$, about one-third to one-half of the fully forced interannual-to-decadal AMOC variance $s_{T}^{2}$ is accounted for by intrinsic processes around $25^{\circ} \mathrm{N}$ and $30^{\circ} \mathrm{S}$, that is, close to the RAPID and SAMOC in situ arrays that are presently (or will soon be) monitoring the AMOC variability. This suggests that only a part of the interannual AMOC variance at these two latitudes may be explained by atmospheric causes. In the subpolar North Atlantic, on the other hand, our results suggest that overturning observational estimates, such as those derived from the existing OVIDE (and future OSNAP) measurements, are strongly related to the atmospheric interannual variability since the intrinsic component only accounts for $5 \%-10 \%$ of the total AMOC variance. About a quarter of the meridional heat transport interannual variability happens to be driven by intrinsic processes near the Gulf Stream and at the southern opening of the basin.

Wavelet power spectra revealed that the AMOC intrinsic variability exhibits an intermittent, stochastic character throughout the $327-\mathrm{yr} 1 / 4^{\circ}$ seasonally forced simulation. At mid- and low latitudes, in the 2-11-yr range, marked spectral peaks spread over wide latitude ranges (as in idealized model studies; e.g., Hazeleger and Drijfhout 2000), but the intensity and frequency of these spectral peaks slowly vary in time, apparently in a random way. The cumulated time over which the most recurrent intrinsic, latitudinally extended spectral peaks are present and significant amounts to about half of the $327 \mathrm{yr}$. In the North Atlantic, some recurrent intrinsic variability peaks overlap the peaks of the AMOC driven by full forcing, suggesting that interannual atmospheric variability modes, such as the North Atlantic Oscillation, may excite certain intrinsic variability modes in the Gulf Stream or the subpolar gyre.

Intrinsic AMOC variability extends beyond decadal time scales. Irregular oscillations are found at the longest periods accessible from our dataset, extending all the way from $35^{\circ} \mathrm{S}$ to $25^{\circ} \mathrm{N}$ in the $15-30-\mathrm{yr}$ band and throughout the whole Atlantic basin in the 50-90-yr band. In both ranges of periods, multidecadal AMOC anomalies tend to propagate northward between $34^{\circ} \mathrm{S}$ and about $30^{\circ} \mathrm{N}$ but seem to propagate northward and southward away from the North Atlantic Current system. Further investigations are needed to identify and quantify the multivariate imprints of intrinsic variability, the dynamical processes involved in its generation, structure, propagation, and nonstationarity, and its dependency to model formulation.

The analysis of our climatological simulations, complemented by Sérazin et al. (2015) in terms of sea level intrinsic variability, raises additional open questions. The appearance of a substantial intrinsic variability when oceanic eddies are resolved suggests that the next generation of coupled models with eddying ocean components will exhibit additional (or perhaps stronger) low-frequency variability modes. Intensified or additional stochasticity might also be expected in future coupled simulations given the intermittency spontaneously generated by the model during $327 \mathrm{yr}$. These results also echo conclusions by Hirschi et al. (2013) and Thomas and Zhai (2013): the low-frequency AMOC variability is not fully deterministic but stochastic in the eddying regime. These findings claim for the use of probabilistic approaches and ensemble modeling strategies in climate-oriented oceanographic studies, as 
proposed, for example, in Penduff et al. (2014), potentially using $1 / 4^{\circ}$ models that proved able to capture most of the intrinsic AMOC variance obtained at $1 / 12^{\circ}$.

Acknowledgments. The authors thank Jean-Michel Brankart, Anne-Marie Treguier, Laurent Terray, and George Nurser for interesting discussions and suggestions. This work is a contribution to MyOcean2, CHAOCEAN, and OCCIPUT projects. It benefited from the DRAKKAR International Coordination Network (GDRI) established between the Centre National de la Recherche Scientifique (CNRS), the National Oceanography Centre in Southampton (NOCS), GEOMAR in Kiel, and IFREMER. The research leading to these results has received funding from the European Community's Seventh Framework Programme FP7/20072013 under Grant Agreement 283367 (MyOcean2). CHAOCEAN is supported by the Centre National d'Études Spatiales (CNES) through the Ocean Surface Topography Science Team (OST/ST). OCCIPUT is supported by the Agence Nationale de la Recherche (ANR) through Contract ANR-13-BS06-0007-01. The computations presented in this study were performed at the Centre Informatique National de l'Enseignement Supérieur (CINES) and at the Institut du Développement et des Ressources en Informatique Scientifique (IDRIS) under allocations made by GENCI. The ORCA025MJM01 and ORCA12-GJM02 simulations were performed as part of the Grands Challenges GENCI/CINES 2008 and 2013, respectively. SG is supported by MyOcean2, GS is supported by CNES and Région Midi-Pyrénées, and TP is supported by CNRS. We also thank two anonymous reviewers for their constructive comments that helped us improve the paper.

\section{REFERENCES}

Baehr, J., J. Hirschi, J.-O. Beismann, and J. Marotzke, 2004: Monitoring the meridional overturning circulation in the North Atlantic: A model-based array design study. J. Mar. Res., 62, 283-312, doi:10.1357/0022240041446191.

Barnier, B., and Coauthors, 2006: Impact of partial steps and momentum advection schemes in a global ocean circulation model at eddy-permitting resolution. Ocean Dyn., 56, 543567, doi:10.1007/s10236-006-0082-1.

Bentsen, M., H. Drange, T. Furevik, and T. Zhou, 2004: Simulated variability of the Atlantic meridional overturning circulation. Climate Dyn., 22, 701-720, doi:10.1007/s00382-004-0397-x.

Biastoch, A., C. W. Böning, and J. R. E. Lutjeharms, 2008: Agulhas leakage dynamics affects decadal variability in Atlantic overturning circulation. Nature, 456, 489-492, doi:10.1038/ nature 07426 .

Blanke, B., and P. Delecluse, 1993: Variability of the tropical Atlantic Ocean simulated by a general circulation model with two different mixed-layer physics. J. Phys. Oceanogr., 23, 1363-1388, doi:10.1175/1520-0485(1993)023<1363:VOTTAO > 2.0.CO;2.
Brodeau, L., B. Barnier, A.-M. Treguier, T. Penduff, and S. Gulev, 2010: An ERA40-based atmospheric forcing for global ocean circulation models. Ocean Modell., 31, 88-104, doi:10.1016/ j.ocemod.2009.10.005.

Bryden, H. L., A. Mujahid, S. A. Cunningham, and T. Kanzow, 2009: Adjustment of the basin-scale circulation at $26^{\circ} \mathrm{N}$ to variations in Gulf Stream, deep western boundary current and Ekman transports as observed by the rapid array. Ocean Sci., 5, 421-433, doi:10.5194/os-5-421-2009.

Cleveland, W. S., and C. Loader, 1996: Smoothing by local regression: Principles and methods. Statistical Theory and Computational Aspects of Smoothing, W. Härdle and M. G. Schimek, Eds., Physica-Verlag Heidelberg, 10-49.

—, E. Grosse, and M.-J. Shyu, 1992: A package of c and FORTRAN routines for fitting local regression models: Loess user's manual. Bell Labs Tech. Rep., 54 pp.

Cravatte, S., G. Madec, T. Izumo, C. Menks, and A. Bozec, 2007: Progress in the 3-D circulation of the eastern equatorial Pacific in a climate ocean model. Ocean Modell., 17, 28-48, doi:10.1016/j.ocemod.2006.11.003.

Cunningham, S. A., and Coauthors, 2007: Temporal variability of the Atlantic meridional overturning circulation at $26.5^{\circ} \mathrm{N}$. Science, 317, 935-938, doi:10.1126/science.1141304.

Delworth, T., S. Manabe, and R. J. Stouffer, 1993: Interdecadal variations of the thermohaline circulation in a coupled oceanatmosphere model. J. Climate, 6, 1993-2011, doi:10.1175/ 1520-0442(1993)006<1993:IVOTTC > 2.0.CO;2.

Deshayes, J., and Coauthors, 2013: Oceanic hindcast simulations at high resolution suggest that the Atlantic MOC is bistable. Geophys. Res. Lett., 40, 3069-3073, doi:10.1002/grl.50534.

Dong, S., S. L. Hautala, and K. A. Kelly, 2007: Interannual variations in upper-ocean heat content and heat transport convergence in the western North Atlantic. J. Phys. Oceanogr., 37, 2682-2697, doi:10.1175/2007JPO3645.1.

Dufour, C. O., J. Le Sommer, J. D. Zika, M. Gehlen, J. C. Orr, P. Mathiot, and B. Barnier, 2012: Standing and transient eddies in the response of the Southern Ocean meridional overturning to the southern annular mode. J. Climate, 25, 6958-6974, doi:10.1175/JCLI-D-11-00309.1.

Dussin, R., and B. Barnier, 2013: The making of DFS 5.1. LGGE Drakkar Project Rep., 40 pp. [Available online at http://www.drakkar-ocean.eu/forcing-the-ocean.]

Eden, C., and J. Willebrand, 2001: Mechanism of interannual to decadal variability of the North Atlantic circulation. J. Climate, 14, 2266-2280, doi:10.1175/1520-0442(2001)014<2266: MOITDV $>2.0 . \mathrm{CO} ; 2$.

Ezer, T., L. P. Atkinson, W. B. Corlett, and J. L. Blanco, 2013: Gulf Stream's induced sea level rise and variability along the U.S. mid-Atlantic coast. J. Geophys. Res. Oceans, 118, 685-697, doi:10.1002/jgrc.20091.

Hall, M. M., and H. L. Bryden, 1982: Direct estimates and mechanisms of ocean heat transport. Deep-Sea Res., 29, 339-359, doi:10.1016/0198-0149(82)90099-1.

Hazeleger, W., and S. S. Drijfhout, 2000: A model study on internally generated variability in subtropical mode water formation. J. Geophys. Res., 105, 13965-13979, doi:10.1029/ 2000JC900041.

Hirschi, J., J. Baehr, J. Marotzke, J. Stark, S. Cunningham, and J.-O. Beismann, 2003: A monitoring design for the Atlantic meridional overturning circulation. Geophys. Res. Lett., 30, 1413, doi:10.1029/2002GL016776.

—, A. T. Blaker, B. Sinha, A. Coward, B. de Cuevas, S. Alderson, and G. Madec, 2013: Chaotic variability of the meridional 
overturning circulation on subannual to interannual timescales. Ocean Sci., 9, 805-823, doi:10.5194/os-9-805-2013.

Johns, W. E., and Coauthors, 2011: Continuous, array-based estimates of Atlantic Ocean heat transport at $26.5^{\circ} \mathrm{N}$. J. Climate, 24, 2429-2449, doi:10.1175/2010JCLI3997.1.

Kanzow, T., and Coauthors, 2007: Observed flow compensation associated with the MOC at $26.5^{\circ} \mathrm{N}$ in the Atlantic. Science, 317, 938-941, doi:10.1126/science.1141293.

Kartashova, E., 2011: Nonlinear Resonance Analysis: Theory, Computation, Applications. Cambridge University Press, 223 pp.

Le Sommer, J., T. Penduff, S. Theetten, G. Madec, and B. Barnier, 2009: How momentum advection schemes influence currenttopography interactions at eddy permitting resolution. Ocean Modell., 29, 1-14, doi:10.1016/j.ocemod.2008.11.007.

Lherminier, P., H. Mercier, C. Gourcuff, M. Alvarez, S. Bacon, and C. Kermabon, 2007: Transports across the 2002 GreenlandPortugal Ovide section and comparison with 1997. J. Geophys. Res., 112, C07003, doi:10.1029/2006JC003716.

Madec, G., and Coauthors, 2012: NEMO ocean engine. IPSL Note du Pole de Modélisation 27, 357 pp. [Available online at http://www.nemo-ocean.eu/content/download/21612/97924/ file/NEMO_book_3_4.pdf.]

Marsh, R., B. A. de Cuevas, A. C. Coward, J. Jacquin, J. J.-M. Hirschi, Y. Aksenov, A. J. G. Nurser, and S. A. Josey, 2009: Recent changes in the North Atlantic circulation simulated with eddy-permitting and eddy-resolving ocean models. Ocean Modell., 28, 226-239, doi:10.1016/j.ocemod.2009.02.007.

McCarthy, G., and Coauthors, 2012: Observed interannual variability of the Atlantic meridional overturning circulation at $26.5^{\circ} \mathrm{N}$. Geophys. Res. Lett., 39, L19609, doi:10.1029/2012GL052933.

Mercier, H., and Coauthors, 2013: Variability of the meridional overturning circulation at the Greenland-Portugal OVIDE section from 1993 to 2010. Prog. Oceanogr., 132, 250-261, doi:10.1016/j.pocean.2013.11.001.

Molines, J.-M., B. Barnier, T. Penduff, A.-M. Treguier, and J. Le Sommer, 2014: ORCA12.L46 climatological and interannual simulations forced with DFS4.4: GJM02 and MJM88. Drakkar Group Experiment Rep. GDRI-DRAKKAR-2014-03-19, 49 pp. [Available online at http://www.drakkar-ocean.eu/global-models/ orca12.]

Penduff, T., J. Le Sommer, B. Barnier, A.-M. Treguier, J. Molines, and G. Madec, 2007: Influence of numerical schemes on current-topography interactions in $1 / 4^{\circ}$ global ocean simulations. Ocean Sci., 3, 509-524, doi:10.5194/os-3-509-2007.
—, M. Juza, L. Brodeau, G. C. Smith, B. Barnier, J.-M. Molines, A.-M. Treguier, and G. Madec, 2010: Impact of global ocean model resolution on sea-level variability with emphasis on interannual time scales. Ocean Sci., 6, 269-284, doi:10.5194/ os-6-269-2010.

$\longrightarrow,-$ _ B. Barnier, J. Zika, W. K. Dewar, A.-M. Treguier, J.-M. Molines, and N. Audiffren, 2011: Sea level expression of intrinsic and forced ocean variabilities at interannual time scales. J. Climate, 24, 5652-5670, doi:10.1175/ JCLI-D-11-00077.1.

_ and Coauthors, 2014: Ensembles of eddying ocean simulations for climate. CLIVAR Exchanges, No. 65, International CLIVAR Project Office, Southampton, United Kingdom, 26-29.

Pierini, S., 2014: Kuroshio extension bimodality and the North Pacific Oscillation: A case of intrinsic variability paced by external forcing. J. Climate, 27, 448-454, doi:10.1175/ JCLI-D-13-00306.1.

Schiermeier, Q., 2013: Oceans under surveillance. Nature, 497, 167-168, doi:10.1038/497167a.

Send, U., T. Kanzow, W. Zenk, and M. Rhein, 2002: Monitoring the Atlantic meridional overturning circulation at $16^{\circ} \mathrm{N}$. CLIVAR Exchanges, No. 25, International CLIVAR Project Office, Southampton, United Kingdom, 31-33.

Sérazin, G., T. Penduff, S. Grégorio, B. Barnier, J.-M. Molines, and L. Terray, 2015: Intrinsic variability of sea level from global $1 / 12^{\circ}$ ocean simulations: Spatiotemporal scales. J. Climate, 28, 4279-4292, doi:10.1175/JCLI-D-14-00554.1.

Thomas, M. D., and X. Zhai, 2013: Eddy-induced variability of the meridional overturning circulation in a model of the North Atlantic. Geophys. Res. Lett., 40, 2742-2747, doi:10.1002/ grl.50532.

Torrence, C., and G. P. Compo, 1998: A practical guide to wavelet analysis. Bull. Amer. Meteor. Soc., 79, 61-78, doi:10.1175/ 1520-0477(1998)079<0061:APGTWA > 2.0.CO;2.

Treguier, A.-M., and Coauthors, 2006: Internal and forced variability along a section between Greenland and Portugal in the CLIPPER Atlantic model. Ocean Dyn., 56, 568-580, doi:10.1007/s10236-006-0069-y.

— global ocean from an eddy-resolving model. Ocean Sci., 10, 243-255, doi:10.5194/os-10-243-2014.

Zhang, R., 2010: Latitudinal dependence of Atlantic meridional overturning circulation (AMOC) variations. Geophys. Res. Lett., 37, L16703, doi:10.1029/2010GL044474. 